\title{
The influence of vowel laryngealisation and duration on the rhythmic grouping preferences of Zapotec speakers
}

\author{
Megan J. Crowhurst ${ }^{\mathrm{a}}$, Niamh E. Kelly ${ }^{\mathrm{a}}$, Amador Teodocio. \\ ${ }^{a}$ The University of Texas at Austin, 305 E. 23rd Street STOP B5100, Austin, Texas, USA, \\ 78712 \\ Corresponding author, Megan J. Crowhurst, mcrowhurst@austin.utexas.edu
}

\begin{abstract}
Some studies of human rhythmic grouping biases (RGBs) have found that listeners tend to perceive greater duration as marking group endings, a "long-last" RGB that has been related to preboundary lengthening in languages. Accumulating evidence from adult and infant studies now suggests that duration-based RGBs are variable, learned, and sensitive to language input. If RGBs can be influenced by language background, then phonologically important features other than duration should be associated with RGBs. In this rhythmic grouping study, native speakers of Betaza Zapotec segmented sequences of syllables in which vowel duration and laryngealised phonation were varied. Results indicated a long-last RGB in all conditions in which duration was varied and a laryngeal-first bias when phonation was varied singly. When duration and phonation were co-varied in the same sequences, duration was the dominant predictor. However, when duration and phonation cues were opposed by alternating modal long and laryngealised short syllables, fewer long-last groupings suggested that in this context, listeners perceived laryngealised phonation as signaling finality. It is argued that in segmenting varied-phonation sequences, listeners were using knowledge of surface phonetic characteristics as opposed to knowledge of the lexical and phonological distribution of laryngealised vowels.
\end{abstract}

Keywords: Iambic-Trochaic Law, speech perception, laryngealisation, rhythmic grouping, Zapotec. 


\section{The influence of vowel laryngealisation and duration on the rhythmic grouping preferences of Zapotec speakers}

\subsection{Introduction}

\subsection{Overview}

More than a century ago, Bolton (1894) and Woodrow (1909) reported that the perception of recurrent units in patterned sound sequences can be shaped by fluctuations in acoustic intensity and duration. They concluded that listeners perceived relatively louder sounds as group-initial, a trochaic pattern, and and longer sounds as group-final, an iambic, "long-last" pattern (the Iambic-Trochaic Law, Hayes 1995). Listeners' rhythmic grouping biases (henceforth RGBs) have been much studied in recent years in experiments with both adults and infants (see $§ 1.2)$. A central theme in this literature relates to this question: do RGBs reflect innate predispositions, or are they learned and shaped by linguistic experience? Evidence from adult studies indicates that duration-based RGBs, in particular, vary depending on language background in listeners who have fully acquired a linguistic system (see §1.2). Findings for infants confirm that durationbased RGBs are learned - differently and at different times, depending on the ambient language (see $\S 1.3)$.

If RGBs have a learned component and are sensitive to language input, then it makes sense to ask whether these biases can be shaped by linguistically important features other than intensity and duration. We studied this issue by conducting a rhythmic grouping experiment with native Zapotec speakers in which vowel duration and vowel laryngealisation were systematically varied. The choice of laryngealisation as a test feature within this population is theoretically interesting in that laryngealised vowels are phonemically contrastive but phonetically diverse in Zapotec. We build a case in $\$ 2$ that the phonological distribution of laryngealised vowels is skewed so that listeners might associate them more strongly with final than with medial syllabic positions within phonological constituents. However, the phonetic markers of the laryngeal percept are different in phrase final and nonfinal positions. Testing listeners using sequences in which laryngeal markers were consistent with nonfinal positions allowed for competing hypotheses as to whether they would use phonological and lexical knowledge, or rather phonetic knowledge, in segmenting rhythmic sequences in which phonation was varied (see $\S 2$ ). Access to Zapotec speakers also provided an opportunity to sample a population that is underrepresented 
in the speech processing literature. As we lay out in $\$ 1.2$, the existing literature on rhythmic grouping suggests questions about the nature of duration-based RGBs and their malleability, depending on the phonetic context in which duration-varied stimuli are presented to human listeners in general. We develop a line of argument in $\S 1.2$ and $\S 1.3$ that a study in which listeners are exposed not only to duration varied singly, but also to duration co-varied with a feature other than intensity can provide new and interesting information about listeners' perceptions of rhythmically organised sound sequences.

\subsection{Are RGBs built in, or learned and sensitive to language input?}

\subsubsection{Intensity-based RGBs may be built-in.}

In typical rhythmic grouping experiments with adults, listeners are presented with sequences in which speech (syllables) or nonspeech sounds (tones or beeps) sounds are alternated in a binary ...ABAB ... pattern. Subjects are tasked with deciding whether sequences break naturally into $\mathrm{AB}$ or BA units. To our knowledge, all such studies testing varied intensity report the trochaic loud-first RGB. Nonspeech studies with this outcome include Rice (1992) for English, Hay and Diehl (2007) for English and French, and Kusumoto and Moreton (1997) and Iversen et al (2008) for English and Japanese. Speech studies reporting a loud-soft grouping bias include Hay and Diehl (2007) for English and French, Bhatara et al (2013) for French and German, Crowhurst and Teodocio Olivares (2014) for Zapotec and English, and Crowhurst (to appear) for Mexican Spanish and English. At least one infant study suggests that a loud-first RGB may be present before infants are typically focusing on specific properties of the ambient language. Hay and Saffran (2012) found that English learners at 6.5 and 9 months used increased intensity together with statistical cues to identify beginnings of bisyllabic "words" in an artificial language. That intensity-based RGBs in adult speakers of diverse languages have been highly consistent and are present early in infant learners tested can be tentatively interpreted as suggesting that humans naturally associate louder sounds with group onsets.

\subsubsection{Pitch-based RGBs are not necessarily based in human language.}

The literature on pitch perception is vast and we cannot hope to do it justice here (see Patel 2008 for a review). In brief, studies that have investigated pitch-based grouping effects have not produced consistent results. Woodrow $(1911,1951)$ asserts that listeners do not use pitch to organise tones into preferred groupings, but Fraisse (1982) claims that listeners associate higher 

organise pitch-varied syllables into high-low units (see below). Conversely, Rice (1992) found that American English speakers associated higher pitch with finality (low-high groupings).

Although pitch-based RGBs are difficult to pin down, there is compelling evidence that a highlow grouping bias must not be specifically rooted in language in that it is not unique to humans. In one cross-species study, Long-Evans rats learned to distinguish tone sequences in which higher and lower pitches alternated from sequences in which pitches were randomly distributed (Mora et al 2013). Not only this, these researchers found evidence that the rats favoured highlow over low-high pitch groupings. In contrast, they found no evidence that the rats could distinguish iambic and trochaic groupings when duration was varied. Adult European Spanish speakers in a companion study also showed a high-low tone grouping bias. Humans and rodents diverged in that the Spanish speakers displayed a long-last RGB for varied duration, an outcome that has been reported for other humans in studies cited below in $§ 1.2 .3$.

\subsubsection{Duration-based RGBs have a learned component.}

Perhaps the clearest evidence that RGBs can have a learned component and may be sensitive to language experience has emerged from studies testing duration-based grouping behaviours. One line of evidence is drawn from crosslinguistic rhythmic grouping studies in which adult speakers of different languages are tested using parallel sound sequences. A second source of support is provided by the results of infant studies, especially when these can be compared with findings for adult speakers of the same languages.

\subsubsection{Studies with adults.}

In a crosslinguistic study with monolingual French and English speaking adults, Hay and Diehl (2007) found that increasing a duration disparity between alternating sounds in a stream of syllables (in a speech condition) or square waves (in a nonspeech condition) increased the magnitude of an iambic, long-last RGB. Bhatara et al (2013) report a parallel result for a similar study in which French and German speakers grouped streams of syllables. Two nonspeech studies without a crosslinguistic component also report long-last outcomes for English speakers (Rice 1992) and Dutch speakers (Vos 1977). In a study using a different methodology, Bion et al (2011) found that adult Italian speakers were better at recognising syllable pairs when they had 
been presented in a long-last (vs. a long-first) pattern in a prior familiarisation phase. As noted in $\S 1.2 .2$, Mora et al (2013) obtained this result in a similar study with adult Spanish speakers.

Other crosslinguistic studies report differences between language groups. Kusumoto and Moreton (1997) and Iversen et al (2008) report a long-last RGB for English speakers who segmented alternating duration-varied tone sequences. However, neither study observed a consistent preference for Japanese speakers exposed to the same sequences. In fact, Iversen et al (2008) report conflicting response patterns: nearly half of their Japanese listeners showed a clear trochaic long-first RGB; a quarter favoured long-last groupings, and the rest had no consistent preference. In a similar nonspeech study with Spanish/Basque bilingual adults, Molnar, Carreiras and Gervain (2014) found a trochaic long-short RGB among Basque-dominant, but a long-last bias among Spanish-dominant participants.

More complex outcomes are reported by Crowhurst and Teodocio Olivares (2014) for a crosslinguistic study with speakers of Zapotec and English and by Crowhurst (to appear) with Mexican Spanish and English speakers. These studies used a more complex design in that listeners were tested on streams of CV syllables in which vowel duration and overall vowel intensity were varied singly (in different sequences), or co-varied in the same sequences. When duration was varied singly, both studies confirmed the long-last RGB reported elsewhere for English. In contrast, Crowhurst and Teodocio Olivares (2014) found a trochaic long-first RGB for Zapotec speakers and Crowhurst (to appear) found no clear grouping preference among Mexican Spanish speakers. However, all language groups in these studies performed similarly in a co-varied condition in which a short/soft syllable was alternated with a longer/louder one. In this condition, the primary predictor of listeners' responses was intensity, but when intensity was held constant, increasing the duration disparity increased long-last groupings.

Published reports suggest that duration-based RGBs are also variable and possibly fragile in that speakers of different languages have displayed different sensitivities to varied duration. In a study with French and German speakers (referred to above), Bhatara et al (2013) observed a long-last RGB in both language groups, but the magnitude of the duration-based effect was greater in the German group. In a second experiment, the long-last grouping bias was replicated for the German speakers, but a small trend favouring long-last groupings in the French group 
was not significant. That Crowhurst (to appear) found a response bias among English but not Spanish speaking participants when duration was varied singly is consistent with Bhatara and her colleagues' observation regarding differing sensitivities. However, that Crowhurst (to appear) did find response biases for sequences in which duration and intensity were varied together suggest that duration-based RGBs are highly context sensitive: it matters whether duration is varied singly, or varied in conjunction with another feature. This is also suggested by Crowhurst and Teodocio Olivares' (2014) finding of a long-first RGB among Zapotec speakers when duration was varied singly, but a long-last effect when duration and intensity were co-varied. These differences cannot be attributed to differences between groups of subjects or settings, because both studies co-mingled singly varied and co-varied sequences in the same blocks of stimuli presented to all participants.

Overall, where RGBs have been observed for duration-based segmentation, most studies have found an iambic, long-last RGB, at least in some conditions. It is noteworthy that most reports are for Indo-European languages and the two contrary long-first outcomes were for non-IndoEuropean languages (a percentage of Japanese speakers in Iversen et al 2008, and Zapotec speakers in one condition in Crowhurst and Teodocio Olivares 2014). This suggests that further tests with speakers of non-Indo-European languages may be useful.

\subsubsection{Infant studies.}

The idea that RGBs are at least partially learned and sensitive to linguistic exposure is supported by infant studies. The outcomes of three studies with children younger than one year suggest that grouping preferences develop differently depending on linguistic exposure (Yoshida et al 2010, Bion et al 2011, and Molnar et al 2014). The studies in this set are noteworthy in that they provide the basis for a comparison with adult speakers of the same languages.

In a preferential listening experiment with Italian 7-month-olds, Bion et al (2011) report that after familiarisation on sequences of alternating pitch-varied syllables, the infants listened for longer when high-low (vs. low-high) pitched bisyllables were played. However, when duration was the varied feature, the investigators found no evidence of a preference. Bion et al (2011) also report that Italian speaking adults in a companion study were better able to remember syllable pairs when they had previously been presented in a high-low (vs. low-high) pitch pattern and in a 
short-long (vs. long-short) pattern during familiarisation. These outcomes indicate that at 7 months, Italian-learning infants already have in place the pitch-based, but not the duration-based grouping bias displayed by Italian adults. Finally, in a study with 9-10 month old infants developing in a bilingual Basque/Spanish environment, Molnar, Lallier and Carreiras (2014) found that accumulated looking times were longer in a Basque-dominant group when presented with tones arranged in an iambic, long-last pattern, whereas Spanish-dominant infants looked for longer when the tones were arranged in long-short pattern. The investigators interpreted this outcome as a novelty effect, and concluded that infants were attending for longer to stimuli with the structure that was less natural for them. From this perspective, the preferences displayed by bilingual infants in this study were congruent with outcomes for Basque- and Spanish-dominant adults, who Molnar, Carreiras and Gervain (2014) observed to have long-first (Basque) and longlast (Spanish) RGBs.

Evidence that sensitivity to duration cues develops as language learning proceeds, and develops differently from other RGBs, is reported by Yoshida et al (2010) and Hay and Saffran (2012). In their artificial language study (see §1.2.1), Hay and Saffran found that English-learning infants displayed the (possibly) universal preference for intensity-based trochaic groupings as early as 6.5 months. In contrast, infants did not use increased duration to identify "word" endings until 9 months. Yoshida et al (2010) exposed English-learning and Japanese-learning infants to alternating duration-varied tone sequences. At 5-6 months, neither the English nor Japanese learners demonstrated a grouping bias. At 7-8 months, the Japanese infants still showed no evidence of a bias, consistent with findings for Japanese speaking adults (see §1.2.3.1) but the English learners had acquired the adult preference for long-last groupings.

In summary, the findings reviewed in $\$ 1.2$ suggest that pitch- and intensity-based RGBs may reflect perceptual predispositions. Although pitch-based grouping effects seem to vary among humans, the ability to segment alternating pitch sequences is not human-specific. Trochaic intensity-based RGBs are widespread and may be universal in humans. It is not clear to what extent duration-based RGBs may be innate, but it is clear that they have a learned component that may be sensitive to linguistic input, and are acquired at different ages, if at all.

\subsection{Why laryngealisation and duration?}


As noted in §1.2.3.1, the most often reported grouping outcome for varied duration is a long-last RGB. Different researchers have drawn a connection between the apparent salience of duration as a cue to finality in rhythmic segmentation tasks and the prevalence of preboundary lengthening patterns (Hay and Diehl 2007, Bhatara et al 2013, Crowhurst and Teodocio 2014, Crowhurst, to appear). Preboundary lengthening effects, in which segments (vowels and/or consonants) are lengthened in syllables at the ends of constituents at all levels of the prosodic hierarchy, vary by language (see Beckman and Edwards 1990 Turk and Shattuck-Huffnagel 2000, 2007 for English; Cambier-Langeveld et al 1997 for Dutch; Hockey and Fagyal 1999 for Hungarian; D'Imperio and Michelas 2010 for French; Nakai 2008 for Finnish; Remijsen and Gilley 2008 for Dinka; Krull 1997 and Carlson et al 2005 for Swedish) and at different levels of the prosodic hierarchy (Wightman et al 1992, Byrd 2000). The presence of preboundary lengthening effects of some variety may well be a language universal (Fletcher 2010), and there is ample evidence that both adult and infant listeners attend to preboundary lengthening in locating constituent edges (Saffran, Newport, and Aslin 1996, Cambier-Langeveld et al 1997; Fletcher 2010).

Laryngealised phonation has a similar demarcative role in some languages; it is associated with endings of higher-order prosodic constituents in the productions of speakers of American and UK varieties of English (Henton and Bladon 1988, Dilley et al 1996, Redi and ShattuckHuffnagel 2001), Hong Kong Cantonese, (Beckman and Venditti 2010), and Swedish (Fant and Kruckenberg 1989), among other languages (see Gobl and Ní Chasaide 2010 and Beckman and Venditti 2010 for further discussion). Studies have also found that listeners use creaky phonation to predict ends of prosodic constituents in English and Swedish (Carlson et al 2005).

That laryngealised phonation, like length, can mark finality in languages raises the question of whether listeners might perceive laryngealised elements to be group-final in a rhythmic segmentation experiment. To date, only one study has explored this question. Kelly et al (2014) presented adult native English speakers with alternating CV syllable sequences in which vowel duration and phonation (the presence/duration of a vowel-final creaky period) were varied either singly or co-varied orthogonally. When listeners segmented alternating syllable sequences in which duration or phonation were varied singly, their responses favoured groupings in which the longer or creaky syllable came last. In a co-varied condition in which a short modal syllable was 

was stronger than when either duration or phonation was manipulated alone. The investigators concluded that their participants had perceived both duration and creaky phonation as signaling finality, and that the effects of these features were additive in combination. In a final condition, duration and phonation cues were configured to work against each other by alternating a short creaky syllable with a long modal syllable. The outcome in this condition was a long-last RGB, indicating that varied duration was the stronger predictor. However, adding creakiness to the shorter syllable reduced the magnitude of the duration effect, which again suggested that listeners had associated creaky phonation with group endings. As English speakers, at least, can use information about laryngealised phonation in a rhythmic grouping study, we wondered whether we could produce similar evidence for speakers of an unrelated language, namely, Zapotec.

A final, general reason for testing the effects of varied duration and phonation in a single study was related to our point (see $\$ 1.2 .3 .1$ ) that duration-based RGBs are sensitive to phonetic context, in particular, whether duration is varied singly or in conjunction with varied intensity. To further explore the malleability of duration-based RGBs, we sought to provide a test in which duration was varied with a different feature, with the intention of comparing any positive results with Crowhurst and Teodocio Olivares' (2014) earlier findings with Zapotec speakers.

\subsection{Background for Betaza Zapotec and the research hypotheses}

San Melchor Betaza Zapotec belongs to a cluster of closely related northern (Xhon) varieties spoken in Oaxaca, Mexico. No published phonetic description exists for Betaza Zapotec, and the information and representations presented here are based on original field research conducted by the third and first authors in Betaza in 2007. The patterns we describe are widespread in Xhon varieties and are confirmed by published descriptions of closely related varieties spoken in Yalálag (Avelino 2001, 2004), San Pedro Cajonos (Nellis \& Hollenbach 1980), Yateé (Jaeger \& van Valin 1982, Jaeger 1983), Yatzachi El Bajo (Pike 1948), and San Bartolomé Zoogocho (Long \& Cruz 2000, Sonnenschein 2004). Mutual intelligibility between these varieties is between $95 \%$ and $100 \%$, in the opinion of the third author, who is a native speaker of Betaza Zapotec and has extensive connections in the region in which it is spoken. 


\subsection{Laryngealised phonation and duration as demarcative features in Betaza Zapotec}

Betaza Zapotec has a three-way phonation contrast among short, modally voiced vowels (/i, o, e, a/) and two classes of laryngealised vowel, traditionally referred to as "checked" vowels (/i', o', e', a'/), and "rearticulated" vowels (/i'i, o'o, e'e, a'a/). Phonetic markers of the laryngeal percept will be discussed later in the section. First, we make the case that there is a probabilistic association between laryngealised vowels, in particular checked vowels, and constituent-final positions in Xhon varieties of Zapotec. While no extensive database exists for Betaza Zapotec, the tendency of laryngealised vowels to occur finally in morphemes and words is confirmed by a manual search of entries in Long and Cruz (2000), a dictionary of San Bartolomé Zoogocho Zapotec, a variety with full mutual intelligibility with Betaza. Table 1 presents a count of $1-4$ syllable lexical entries (affixes and words) containing a checked or laryngealised vowel and the syllabic position in which it occurs. Homophones were counted separately, but a single morpheme was not counted twice. (For example, yeche' 'thorn' and bi'a 'prickly pear cactus' were counted once each, but the compounds yeche' bi'a was not counted again.) Zapotec is an inflecting language in which noun and verb roots combine with consonantal prefixes and with suffixes that can add syllables to the root. Given that roots contain up to and never more than 3 syllables, the tetrasyllables in Table 1 are morphologically complex, as are many of the trisyllables. Table 2 summarises the information for the $2-4$ syllable items in a table of proportions. Overall, laryngealised vowels are more common in final than nonfinal syllables in Zoogocho Zapotec lexical items containing them. This is true for checked vowels in words of any length, and for rearticulated vowels in bisyllables. This pattern is reversed in words of 3 and 4 syllables with rearticulated vowels. (As suffixes contain modal or checked vowels, the higher proportion of trisyllables and tetrasyllables with non-final rearticulated vowels reflects the combination of a root ending in $/ \mathrm{V}^{\prime} \mathrm{V} /$ with suffixes containing modal or checked vowels.) Of the two laryngealised categories, checked vowels are the more common: in our count, there are 3.65 times as many checked as rearticulated vowels.

Table 1. Counts for laryngealised vowels by syllable position in affixes and words of $1-4$ syllables in San Bartolomé Zoogocho Zapotec (Long and Cruz 2000).

\begin{tabular}{cc|cc|ccc|cccc|c}
\hline & Mono- & \multicolumn{2}{|c|}{ Disyllables } & \multicolumn{2}{|c|}{ Trisyllables } & \multicolumn{4}{|c|}{ Tetrasyllables } & \\
& syllables & $1^{\text {st }}$ & $2^{\text {nd }}$ & $1^{\text {st }}$ & $2^{\text {nd }}$ & $3^{\text {rd }}$ & $1^{\text {st }}$ & $2^{\text {nd }}$ & $3^{\text {rd }}$ & $4^{\text {th }}$ & Totals \\
\hline /i'/ & 22 & 32 & 21 & 13 & 12 & 15 & 0 & 3 & 3 & 2 & 123 \\
/e'/ & 22 & 15 & 167 & 11 & 31 & 167 & 0 & 22 & 4 & 98 & 537 \\
/a'/ & 74 & 34 & 227 & 22 & 19 & 87 & 1 & 23 & 1 & 25 & 513
\end{tabular}




\begin{tabular}{cc|cc|ccc|cccc|c} 
/o'/ & 19 & 13 & 90 & 5 & 12 & 44 & 3 & 7 & 1 & 10 & 204 \\
\hline All $/ V^{\prime} /$ & 137 & 94 & 505 & 51 & 74 & 313 & 4 & 55 & 9 & 135 & 1,377 \\
\hline /i'i/ & 16 & 5 & 23 & 4 & 0 & 2 & 0 & 2 & 0 & 0 & 52 \\
le'e/ & 44 & 6 & 33 & 2 & 1 & 5 & 2 & 1 & 0 & 2 & 96 \\
/a'a/ & 70 & 22 & 40 & 11 & 1 & 6 & 1 & 4 & 0 & 1 & 156 \\
/o'o/ & 27 & 16 & 11 & 6 & 4 & 4 & 4 & 1 & 0 & 0 & 73 \\
\hline All /V'V/ & 157 & 49 & 107 & 23 & 6 & 17 & 7 & 8 & 0 & 3 & 377 \\
\hline
\end{tabular}

Table 2. Lexical counts and proportions for laryngealised vowels in final vs. nonfinal positions in words of 2-4 syllables in San Bartolomé Zoogocho Zapotec.

\begin{tabular}{ccc|cc|cc|cc}
\hline & \multicolumn{2}{c|}{ Disyllables } & \multicolumn{2}{c|}{ Trisyllables } & \multicolumn{2}{c}{ Tetrasyllables } & \multicolumn{2}{c}{ Totals } \\
& Nonfin & Final & Nonfin & Final & Nonfin & Final & Nonfin & Final \\
\hline All /V'/ & $94(.16)$ & $505(.84)$ & $125(.29)$ & $313(.71)$ & $68(.33)$ & $135(.67)$ & $287(.23)$ & $953(.77)$ \\
All /V'V/ & $49(.31)$ & $107(.69)$ & $29(.63)$ & $17(.37)$ & $15(.83)$ & $3(.17)$ & $93(.42)$ & $127(.58)$ \\
\hline
\end{tabular}

In addition to the evidence that laryngealised vowels are asymmetrically distributed with a final bias in the lexicon, there is informal evidence that markers of the laryngeal percept may be reduced or absent in non-final positions in speech. Morphological and syntactic concatenation can produce words, compounds, or phrasal units containing more than one laryngealised vowel. Figure 1 presents sound waves for two tokens of beko' yo'o 'coyote' uttered by a female speaker. (Items in in Figures $1-7$ are taken from Teodocio-Olivares and Crowhurst 2007a,b.) It can be seen that the checked vowel $/ \mathrm{o}^{\prime} /$ in beko' is laryngealised in Figure 1a, but almost fully modal in Figure 1b. Similarly, in Figure 2a, the final vowel /e'/ in yeche' 'thorn' is laryngealised, but this vowel is delaryngealised in Figure 4 where yeche' occurs nonfinally in yeche' bia 'spine of the prickly pear cactus', a phrasal unit.

[Insert Figure 1 and 2 about here.]

Turing to duration, detailed phonetic studies have not to our knowledge specifically investigated preboundary lengthening. However, given that preboundary lengthening effects are widely attested and possibly universal, we think it is likely that they are present in Xhon Zapotec varieties as well. In this regard, Pike's (1948) description of Yatzachi Zapotec is suggestive; he notes that " $[\mathrm{v}]$ owels toward the front of a long word are frequently shorter than vowels in the last two syllables of a word or phrase" in Yatzachi Zapotec (Pike 1948:167). While we are not able to provide quantitative support for Betaza Zapotec, we proceed under the provisional assumption that domain-final vowel lengthening effects are also present in this variety. 
Given the distributional associations between length and finality, and laryngealised vowel categories and finality in Zapotec, we might expect Zapotec speakers to use their knowledge of these patterns in segmenting rhythmically alternating sequences. We predicted that if Zapotec speakers interpret increased duration and laryngealised phonation as signaling finality, then they should use an END-BASED segmentation strategy, with the outcomes in (1).

\section{(1) End-based segmentation hypothesis}

a. The proportion of laryngeal-last groupings will be higher than laryngeal-first groupings when phonation is varied.

b. The proportion of long-last groupings will be higher than long-first groupings when duration is varied.

Given patterns associated with laryngealised phonation and duration in Betaza Zapotec, (1a) and (1b) are not the only possible outcomes for Zapotec speakers. In sections 2.2 and 2.3, we develop competing hypotheses for phonation-based and duration-based segmentation, respectively.

\subsection{Phonetic differences between phrase final and nonfinal laryngealised vowels}

In this section, we make two points that will feed into the study's hypotheses. The most important point is that laryngealised vowels have different expressions in phrase-final and nonfinal positions: in particular, checked vowels are reliably characterised by final closure in phrase final positions but not in nonfinal positions, where laryngeal markers are more variable and overlap with phonetic markers of laryngealisation in rearticulated vowels. The second point is that there is much surface variability in the duration of laryngealised vowels. While there is overlap, rearticulated vowels are generally longer than checked vowels in similar phonetic contexts. In fact, Sonnenschein (2004) describes rearticulated vowels in Zoogocho Zapotec as creaky voiced vowels and transcribes them as long /VV/. In other respects, the phonetic expressions of nonfinal checked and rearticulated vowels can be remarkably similar, including the timing of markers associated with the laryngeal gesture. The main point we wish to establish is that surface differences in duration associated with laryngealised vowels phonetically natural for Zapotec speakers, and co-varying laryngealised phonation and vowel duration in stimuli presented to subjects in our study did not introduce differences that are inconsistent with the sound patterns of the language. 

pause, checked vowels end in a visibly creaky period culminating in full glottal closure. In other respects, however, markers of laryngealisation vary. In Figure 2a and Figure 3, visibly creaky phonation may be present at the end of the final checked vowel. In Figure $3 b, / a$ ' is characterised by aperiodicity as well as creakiness throughout the vowel. In Figure 3b, the sound wave for the word labada' 'gourd' is shown in its entirety to provide examples of modal vowels for comparison. In Figure 3c, laryngealisation in /e'/ is manifest in aperiodic voicing cycles in the second half of the vowel, with no visible creakiness. Phrase-final rearticulated vowels are typically realised with a medial period of laryngealisation, as shown in Figure 4. Phrase-final rearticulated vowels typically end in breathiness, but in this they are no different from phrasefinal modal vowels. It can also be seen in Figures $1-4$ that rearticulated vowels are characteristically longer than checked vowels.

[Insert Figures 3 and 4 about here.]

Setting aside the characteristic glottal closure associated with phrase final checked vowels, laryngealised vowels in both categories are phonetically diverse and they are not reliably distinguished by the localisation of laryngeal markers within the vowel, nor by the particular phonetic realisation of laryngeal markers. As we noted for checked vowels, laryngealisation may be signaled by an aperiodic wave form, with or without visible creakiness, in rearticulated vowels as well. In Figure 1, the sound wave for the rearticulated vowel /o'o/ is marked by creaky and aperiodic periods throughout the first half of the vowel, followed by a modal segment. Figure 5 presents two tokens of yinha' ya'a 'green chile'. In Figure 5a, we see that the first half of /a'a/ is modally voiced, and that the second half of the vowel is characterised by visible creakiness and aperiodicity in places. However, in figure $5 \mathrm{~b}$, the wave form for /a'a/ is aperiodic with no visible creakiness through the first two thirds of the vowel, followed by a modally voiced segment.

[Insert Figure 5 about here.]

Because laryngealised markers are variable and not precisely localised on vowels, there is often little to distinguish non-final checked vowels from rearticulated vowels. In Figure 6a, we see that 
laryngeal markers (creak, aperiodicity and lowered f0) associated with /i'/ in bi'abel xhinje 'hallucinogenic mushroom sp.' extend not only through the vowel, but perseverate through the following $\mathrm{VC}$ sequence as well. In Figure 6b, the vowel /e'/ in yixe' presents an example of a checked vowel in which the timing of the laryngeal gesture is medial and indistinguishable from that in a canonical rearticulated vowel (cf. Figure 4). Figure 7 presents two tokens of the word $y a^{\prime} d a o^{\prime}$ ' forest' in which markers of laryngealisation extend through the first half of the vowel $/ a \%$. In Figure $7 \mathrm{a}$, laryngealisation in the vowel /ja $/$ is manifest as visible creak throughout the beginning of the vowel followed by an aperiodic wave form at the end (compare with /o'o/ in Figure 1). In Figure $7 \mathrm{~b}$, laryngealisation in $/ \mathrm{ja} /$ as a lower intensity aperiodic waveform in the first half of the vowel (compare with /a'a/ in Figure 5b). The timing and expression of laryngeal markers in nonfinal rearticulated vowels are similarly variable.

\section{[Insert Figures 6 and 7 about here.]}

As Zapotec is a tone language, it is important to note that laryngealised vowels do not have predictable f0 properties. F0 damping, commonly associated with laryngealised vowels (Redi and Shattuck-Hufnagel 2001), can be seen in many of our examples in which there is no visible pitch track. However, laryngealised vowels do not represent a special tone category; laryngealised and modal vowels support the same set of contrastive tones. In Figures 3-5, for example, we see examples of laryngealised vowels with mid, high, and falling tone.

Given that checked vowels, the most common laryngealised category (see §2.1), are distinct in final and nonfinal positions, it was possible to entertain a hypothesis that competed with the endbased segmentation prediction for varied phonation. In our study, phonation-varied sequences presented to Zapotec speakers were prepared with laryngealised vowels that were more typical of non-final phrasal positions (see $\S 4$ for details). We considered that as an alternative to (1a), rather than using a lexical/phonological strategy in segmenting sequences in which phonation was varied, their grouping strategies might be more sensitive to the competing phonetic information, in which case we expected to find a laryngeal-modal RGB, as stated in (2).

(2) Phonetic laryngeal segmentation hypothesis: The proportion of laryngeal-first groupings will be higher than laryngeal-last groupings when phonation is varied. 


\subsection{Duration patterns.}

Finality is not the only contrast that can be signaled by duration: it is well known that patterns of increased duration are associated with the stress contrast in numerous languages, both as an acoustic property of speakers' productions and as a perceptual cue to the identification of stressed syllables (see Beckman and Edwards 1990, for English, and Fletcher 2010 for an extended crosslinguistic review). In addition to final lengthening patterns in Betaza Zapotec, differences in vowel duration are conditioned by stress and the class of a following consonant. In Betaza Zapotec, stress regularly falls on a root syllable, never on suffixes. This means that stress falls on nonfinal syllables in verbs, which take number agreement suffixes (e.g. ble'lgakba ['ble'll-gak-ba] 'They saw (animal subject)', goxhonjlhe [go-'zonj-le] 'you plur. fam. will run'). In nouns, stress regularly falls on the penultimate syllable of polysyllabic roots. Therefore, stress on final syllables is generally limited to indefinite monosyllabic nouns, which are unsuffixed. Betaza's nonfinal stress pattern is typical of Xhon varieties. According to Nellis and Hollenbach (1980:100), primary stress falls on the penultimate syllable of a polysyllabic root ending in an open syllable with a modal or checked vowel, otherwise on the root-final syllable in Cajonos Zapotec, a closely related variety. As closed syllables are rare, this means that penultimate stress is the unmarked pattern in unsuffixed polysyllables. Stress also falls on nonfinal syllables in Zoogocho Zapotec (Sonnenschein 2004).

All Zapotec varieties have a highly salient contrast between fortis and lenis consonants. Excepting glides, all consonants in Betaza Zapotec come in fortis/lenis pairs. Fortis consonants are longer than lenis consonants in both the obstruent and sonorant classes. Fortis obstruents are phonetically realised as voiceless, while their lenis counterparts are voiced and tend to be spirantised intervocalically). Increased vowel duration is a primary marker of stress, but only before lenis consonants. Before fortis consonants, stressed vowels remain short and the consonant is lengthened (relative to its duration after an unstressed vowel). ${ }^{1}$

Our competing hypothesis for duration was that instead of the end-based segmentation strategy described in (1), listeners might instead adopt a STRESS-BASED segmentation strategy, in which case we expected to find a long-short RGB when they segmented sequences in which

\footnotetext{
${ }^{1}$ These statements apply to all Xhon varieties. For a recent, high-quality phonetic description of Yalálag Zapotec, see Avelino (2001, 2004). See also Jaeger (1983) for Yateé and Nellis and Hollenbach (1980) for Cajonos Zapotec.
} 
alternating long and short vowels were separated by lenis consonants, as stated in (3). Listeners should not associate increased vowel duration with stress sequences containing fortis consonants, and here we expected to find a long-last RGB consistent with the end-based strategy.

(3) Stress based segmentation hypothesis: The proportion of long-first groupings will be greater than long-last groupings in duration-varied sequences containing lenis consonants (voiced stops).

\subsection{The experiment}

\subsection{Method}

\subsubsection{Overview}

To explore the hypotheses developed in the previous sections, we conducted a rhythmic grouping study with adult native speakers of Zapotec in which the manipulated features were vowel duration, phonation quality (modal vs. laryngealised vowels), and consonant quality (voiced vs. voiceless stops). All aspects of this experiment were conducted under a protocol approved by the Institutional Review Board of the University of Texas at Austin. Streams of coarticulated CV syllables were prepared in which either duration, or phonation, or both were varied in an alternating pattern. To provide a baseline for comparison, two short modally voiced syllables were alternated to serve as controls. In a Duration condition, duration was varied at a fixed ratio. In a Laryngeal condition, a short modal and a short laryngealised syllable were alternated. There were also two conditions in which duration and phonation were co-varied in the same sequences. In an Overlapped condition, a short modal syllable was alternated with a long laryngealised one, and in an Opposed condition, a long modal and a short laryngealised syllable were used. A final condition was included to test for differences associated with the lenis/fortis consonants, which might influence whether or not listeners interpreted increased vowel duration as a stress-marking cue (before lenis consonants). For this condition, parallel series were prepared in which the alternating syllables had either voiced stop onsets ( $g e$ and $d e$, representing the lenis class), or voiceless stop onsets ( $k e$ and te, representing the fortis class). Sequences were constructed so that syllables with velar onsets ( $g e$ or $k e$ ) alternated with coronal onsets ( $d e$ or $t e$ ). Listeners were tasked with indicating whether they thought the sequences they were hearing broke naturally into dege/teke or gede/kete units. The design of the stimulus set is shown in Table 3, and the values assigned to alternating syllables are shown in Table 4 in $§ 3.1 .2 .2$. 
Table 3. Experimental design.

\begin{tabular}{|c|c|c|c|}
\hline \multirow{2}{*}{ Condition } & & \multicolumn{2}{|c|}{ Combinations } \\
\hline & & Voiced onsets & Voiceless onsets \\
\hline CONTROL & Short mod vs short mod & short mod $d e$ vs. short mod $g e$ & short mod te vs. short mod ke \\
\hline LARYNGEAL & Short lar vs. short mod & $\begin{array}{l}\text { short mod de vs. short lar ge } \\
\text { short mod ge vs. short lar } d \underline{e}\end{array}$ & $\begin{array}{l}\text { short mod te vs. short lar ke } \\
\text { short mod ke vs. short lar } t \underset{e}{\text { en }}\end{array}$ \\
\hline DURATION & Short mod vs. long mod & $\begin{array}{l}\text { short mod de vs. long mod gee } \\
\text { short mod ge vs. long mod dee }\end{array}$ & $\begin{array}{l}\text { short mod te vs. long mod kee } \\
\text { short mod ke vs. long mod tee }\end{array}$ \\
\hline OVERLAPPED & Short mod vs. long lar & $\begin{array}{l}\text { short mod de vs. long lar gee } \\
\text { short mod ge vs. long lar dee }\end{array}$ & $\begin{array}{l}\text { short mod te vs. long lar kee } \\
\text { short mod ke vs. long lar tee }\end{array}$ \\
\hline OPPOSED & Short lar vs. long mod & $\begin{array}{l}\text { short lar de vs. long mod gee } \\
\text { short lar ge vs. long mod dee }\end{array}$ & $\begin{array}{l}\text { short lar te vs. long mod kee } \\
\text { short lar ke vs. long mod tee }\end{array}$ \\
\hline
\end{tabular}

* The terms "modal" and "laryngealised" are abbreviated as "mod" and "lar".

\subsubsection{Stimulus preparation}

\subsubsection{Modal syllables}

Stimulus production began with natural speech. For the modal sequences, the third author, a native speaker of Betaza Zapotec, recorded coarticulated sequences of modal syllables, alternating between coronal and velar onsets, at a relaxed pace. Sequences were recorded for both the voiceless (i.e. ...te-ke-te-ke-te...) and the voiced conditions (i.e. ...de-ge-de-ge-de...). Recorded sequences were counterbalanced so that half began with the velar and half with the coronal syllable. Using this method made it possible to select coronal-initial and velar-initial tokens from equivalent (odd or even) positions in original recordings, and in this way avoid positionally-related differences between alternating syllables that were not being tested. Modal syllable tokens $t e, k e, d e, g e$ were excised from noninitial, odd-numbered positions for further manipulation in Praat (version 5.3.40 for Macintosh, Boersma and Weenink 2013). Syllable tokens were cut at zero crossing lines from the onset of the vowel to the beginning of the next syllable's vowel. Selected tokens were closely matched for vowel duration, mean level intensity, level pitch contour in comparable f0 ranges. These tokens were edited using standard Praat functions to normalise overall intensity, pitch, and duration. Pitch was normalised by raising or 
lowering pitch points across the board in the selected syllables so that f0 values were in the end comparable. These procedures produced 8 new syllables each (4 short syllables te, ke, ge, de and 4 long syllables tee, kee, gee, dee) for use in modal sequences.

In Betaza Zapotec (as in many languages, including English), voiced stops are shorter than voiceless stops in comparable positions and vowels are consistently longer before voiced than voiceless stops. Given that stimulus production began with natural speech, these differences are present in our stimulus set across sequences. To avoid differences in consonant length within the same sequences, intervocalic consonants ([t, k] in voiceless and $[\mathrm{d}, \mathrm{g}]$ in voiced sequences) were adjusted to have the same durations (see Table 2 in \$3.1.2.2). Syllable tokens selected from the original recordings were chosen to have vowels whose durations were intermediate in the range between short and long. To create duration-varied sequences, vowel duration was manipulated by removing full voicing cycles from the selected token where necessary to produce short vowels and adding full voicing cycles for long vowels. Sites for insertion/deletion were selected subjectively by the authors, taking care to preserve the characteristic contours of the original syllable token and to avoid abrupt local transitions. Mean level intensity was normalised to 68 $\mathrm{dB}$ in all syllables, and intensity was verified after adjustments to duration were made.

\subsubsection{Laryngealised syllables}

To produce short and long syllables for the sequences in which phonation was varied, the speaker recorded coarticulated sequences in which all of the alternating syllables contained either checked vowels and (te'/ke' and ge'/de') or rearticulated vowels (te'e/ke'e and ge'e/de'e) to represent the longer category. While these sequences were not entirely natural in that they juxtaposed laryngealised syllables, the speaker was free to continue recording until he was satisfied with the results. Tokens were selected based on the extent to which they sounded natural as representatives of the categories they represented in the opinion of the third author. It was not possible to select a perfectly matched series of laryngealised syllable tokens for two main reasons. First, in the Zapotec speech of our recorder, laryngealised vowels are typically creaky between voiceless stops, but they tend to have an aperiodic sound wave with little or no visible creakiness between voiced stops. Secondly, laryngeal markers tended to be expressed mostly in mid-vowel between voiced stops and throughout much of the latter part of the vowel between voiceless stops. As these characteristics may reflect natural differences in Betaza 
Zapotec, our editing procedures preserved them insofar as adjustments to duration (made as described above for the modal series) preserved, where possible, ratios of modal to laryngealised phonation present in the original vowels. Since these laryngealised vowels were created to reflect length differences and do not necessarily represent checked and rearticulated vowels in our framework, we will represent them phonetically, using the diacritic for laryngealisation beneath the vowels. Sound waves and spectrograms for the laryngealised syllables used in the study are shown in Figures 8 and 9. The final set of syllables used in constructing stimuli had the measurements shown in Table 4 for vowel duration, the period from vowel onset to vowel onset, and pitch.

Table 4. Phonetic properties of edited syllables used in stimulus construction.

\begin{tabular}{|c|c|c|c|c|c|c|c|c|c|c|}
\hline Type & & $\begin{array}{c}\text { Vowel } \\
\text { dur }\end{array}$ & $\begin{array}{c}\mathrm{V} \% \\
\text { of syll } \\
\end{array}$ & $\begin{array}{c}\text { V-to-V } \\
\text { dur }\end{array}$ & $\begin{array}{c}\text { Pitch } \\
(\operatorname{avg~Hz})\end{array}$ & & $\begin{array}{c}\text { Vowel } \\
\text { dur }\end{array}$ & $\begin{array}{c}\mathrm{V} \% \\
\text { of syll } \\
\end{array}$ & $\begin{array}{c}\text { V-to-V } \\
\text { dur }\end{array}$ & $\begin{array}{c}\text { Pitch } \\
(\operatorname{avg~Hz})\end{array}$ \\
\hline \multirow[t]{2}{*}{ Short mod } & $d e$ & 189 & .68 & 278 & 100.6 & te & 133 & .43 & 306 & 107.8 \\
\hline & $g e$ & 193 & .67 & 289 & 100.3 & ke & 134 & .43 & 309 & 106.1 \\
\hline \multirow[t]{2}{*}{ Short lar } & $d e$ & 190 & .67 & 284 & 99.3 & te & 140 & .44 & 317 & 104.1 \\
\hline & $g e$ & 189 & .66 & 285 & 98.0 & $k e$ & 138 & .45 & 309 & 96.2 \\
\hline \multirow[t]{2}{*}{ Long mod } & dee & 284 & .75 & 377 & 100.5 & tee & 257 & .59 & 434 & 108.2 \\
\hline & gee & 283 & .75 & 379 & 100.1 & kee & 253 & .60 & 425 & 107.6 \\
\hline \multirow[t]{2}{*}{ Long lar } & dee & 291 & .76 & 385 & 99.5 & tee & 257 & .61 & 421 & 106.3 \\
\hline & ge & 295 & .75 & 391 & 100.3 & kee & 250 & .59 & 424 & 108.5 \\
\hline
\end{tabular}

[Insert Figures 8 and 9 about here.]

\subsubsection{The sequences}

To produce test stimuli, syllables were combined into alternating sequences according to the design in Table 3. Sequences measured 10-11 seconds in length and had between 28 and 36 syllables, depending on their durations. Sequences consisted of a whole number of syllable pairs, either dege or gede. As in Hay and Diehl (2007), sequence onsets were masked by blending the first 5 seconds of the sequence with a segment of white noise, created in Praat, whose initial intensity was $67 \mathrm{~dB}$. Over this 5 second period, the noise was ramped down to $0 \mathrm{~dB}$, and the alternating syllables were ramped up from $0 \mathrm{~dB}$ to their maxima. An additional $500 \mathrm{~ms}$ segment of $67 \mathrm{~dB}$ white noise was added to sequence endings to backwards-mask the string-final syllable as an extra precaution, should participants listen for that long.

\subsubsection{Participants}



age from late teens to $40 \mathrm{~s}$, with the exception of one female speaker in her 60s. All were native, dominant speakers of Zapotec, although most had learned some Spanish in school or through working outside the community. All participants spoke only Zapotec at home and in the Betaza community, where Zapotec is used almost exclusively by insiders. The experiment was conducted in two sessions (see §3.1.3) and all participants included in the analysis participated in both. Not included in the analysis were four additional subjects who took part in only one session, and a fifth who attended both sessions, but completed only one of five blocks in session 1. Subjects were recruited in Betaza through the extended social network of the third author and were paid 100 Mexican pesos per session.

\subsubsection{Experimental procedures}

Participants were tested in small groups of 6-8, seated around a large rectangular table in a quiet room (approximately 30' $\mathrm{x}$ 15') in a private home. The experiment was controlled by the software program SuperLab 4.0 (Cedrus Corporation) running on a MacBook Pro laptop computer. Sequences were presented in free field at a comfortable volume over a portable Bose Soundlink loudspeaker (model 404800) connected by cable to the computer's audio output jack and placed at one end of the table. The experiment was conducted in two sessions over a period of four days. All subjects heard sequences with voiced stops in session 1 and sequences with voiceless stops in session 2. Sessions were deliberately run in this order given that we had competing hypotheses for the voiced but not the voiceless condition. We hypothesized that in the duration condition, participants might show a long-last RGB if they perceived increased duration demarcatively, or a long-first RGB if they perceived it as a stress-marking cue. We had no reason to think that subjects would adopt anything other than an end-based strategy when segmenting voiceless stop sequences. Had subjects been exposed to the voiceless sequences first, it wouldn't be clear whether a long-last outcome in the voiced condition, if obtained, was due to the confounding effect of having heard the voiceless sequences first. As noted, in $\$ 3.1 .2$, all subjects whose data was included in the analysis took part in both sessions. During the testing portion of each session, stimuli were presented to participants in 5 test blocks, in which each of the 18 sequences in the stimulus set was presented once. Each block also included 6 additional sequences in which all syllables were laryngealised as filler items; these were not included in the 
analysis. The order of sequences within blocks was automatically randomised by the software each time a block was run.

The Zapotec language environment was reinforced in several ways. Sessions were conducted exclusively in Betaza Zapotec by the third author. Detailed verbal instructions (in Zapotec) were reinforced by diagrams drawn on large sheets of paper taped to a wall. The experimenter kept pace during testing by intermittently calling out numbers of trials in Zapotec. Only Zapotecspeaking members of the community were present during testing. Participants saw no text in Spanish until the end of the experiment. They provided verbal consent prior to testing and signed a consent form written in Spanish at the end of the session. An information sheet offered to participants after testing was written in Spanish as it was impractical to translate this material into Zapotec.

Each participant was given a stapled booklet of 6 pages. The first page provided examples showing how to indicate a response correctly and how to strike out a line in case a trial was missed. (These models were identical to those diagrammed on the sheets of paper taped to the wall.) The text on this page (a short sentence for each example) was in Zapotec for its symbolic value, even though most participants, while literate in Spanish, do not read Zapotec. The 5 remaining pages were response sheets, one per block, with the block number clearly indicated. Response sheets were printed with numbered, underlined blanks, one for each trial. As an indirect measure of listeners' grouping tendencies, they were tasked with indicating whether they thought each sequence broke most naturally into gede/kete or dege/teke pairings by printing the initial letter of the grouping they perceived $(g / k$ or $t / k)$ in the blank for the trial on the response sheet. To the right of each response, they were asked to provide a confidence rating by printing 1 if they were certain of their response or 2 if they had experienced difficulty in reaching a decision. They were instructed to wait until after the initial masking noise had faded completely away before making a decision, and to respond while the recording was still playing. Testing was preceded by four practice items and feedback on these. The entire experiment (introduction, testing, and informed consent procedures) took roughly 50 minutes to complete. Time spent listening to sequences ran to about 25 minutes, including breaks.

\subsubsection{Statistical analysis}



sequences (18 voiceless and 18 voiced), each with 5 repetitions (for intra-rater reliability) over the course of the study for 22 participants. (We note that because sequences were counterbalanced for initial syllable, every combination of values we tested was actually heard 10 times over the course of the experiment.) There were 19 missing observations (less than .05\% of the maximum), leaving a total of 3,941 data points for the analysis. Cross-tabulations based on the raw data we obtained, organised by condition, are presented in Tables 5-7 in Appendix A.

To test for the significance of any trends, mixed effects logistic regression models were fit to the response data using the glmer function in the Matrix library (Bates and Maechler 2013) of the statistical software package R (R Core Team 2013), with SUBJECT treated as a random effect. This method estimated the maximum likelihood of a TeKe decision, the positively coded response category. (TeKe represented a unit of grouping in which the first syllable onset was a coronal and the second a velar, a dege or teke response, depending on consonant fortition class.) The contents of the models constructed were determined by the study's hypotheses. The predictors DURATION and CREAK were coded as factors with three levels, a baseline nodifference condition and two levels representing the association of length or creakiness with either the coronal or the velar syllable. ONSET was coded as a factor with two levels encoding whether consonants were voiceless or voiced, with voiceless as the comparison category. An interaction CREAK*DURATION was included in the model given that we expected effects associated with duration and laryngealisation to differ depending on whether they were manipulated singly or together. A term ONSET*DURATION was included to test whether listeners' grouping decisions were affected by consonant class when duration varied. Confidence ratings were not included in the statistical analysis because not all subjects provided ratings according to the instructions, and post-session feedback indicated that a number of subjects had not understood their purpose.

\subsection{Results}

To revisit our hypotheses, we expected participants to use an end-based segmentation strategy if they were interpreting increased duration as signaling finality, and if they were using information about the lexical and phonological distribution of laryngealised vowels to segment sequences. If so, then the outcomes should be long-last and laryngeal-last RGBs when duration and phonation 
were varied singly. Alternatively, a long-first RGB in the voiced but not in the voiceless stop condition would suggest that listeners were associating increased duration with stress, and a laryngeal-first RGB would be more consistent with their using phonetic knowledge (laryngealised vowels with no glottal closure or extended breathiness occur in nonfinal, not final phrasal positions). We had no basis for specific predictions for the co-varied conditions, given our competing hypotheses in the singly varied conditions. However, we expected that the dominant response in the co-varied conditions would provide information about whether one feature was more strongly associated with listeners grouping preferences than the other.

Table 8 presents the output of the model that best fit the response data $\left(\chi^{2}=21.277, \mathrm{df}=6, \mathrm{p}=\right.$ .0016). The best-fitting model was determined using the method of forward addition. Starting with the intercept-only model, Fit(0), terms were added in a stepwise manner. Every model Fit(n+1), 1 an added term, was compared with the more parsimonious Fit(n) using ANOVA. This process continued as long as addition significantly improved goodness-of-fit and ended when the significance level associated with $\chi^{2}$ fell below the $\alpha$ level, .05 . Terms were added in the following order: DURATION; ONSET*DURATION; and CREAK*DURATION. ${ }^{2}$

Table 8. Content of the best-fitting model predicting TeKe responses.

\begin{tabular}{lrrrrrl}
\hline & Coef. & \multicolumn{1}{c}{ OR } & SE & \multicolumn{1}{c}{$\mathrm{z}$} & $\mathrm{p}$ & \\
\hline Intercept & 0.018 & 1.02 & 0.115 & 0.152 & 0.8790 & \\
CREAK (KE) & -0.295 & .74 & 0.136 & -2.169 & 0.0301 & $*$ \\
CREAK (TE) & 0.242 & 1.27 & 0.137 & 1.772 & 0.0764 & \\
DURATION (KE) & 1.434 & 4.20 & 0.175 & 8.208 & $<0.00001$ & $* * *$ \\
DURATION (TE) & -1.475 & .23 & 0.174 & -8.477 & $<0.00001$ & $* * *$ \\
ONSET (VOICED) & 0.150 & 1.16 & 0.111 & 1.346 & 0.1783 & \\
CREAK (KE) * DURATION (KE) & 0.244 & 1.28 & 0.210 & 1.158 & 0.2469 & \\
CREAK (TE) * DURATION (KE) & -0.522 & .59 & 0.208 & -2.513 & 0.0120 & $*$ \\
CREAK (KE) * DURATION (TE) & 0.494 & 1.64 & 0.206 & 2.401 & 0.0164 & $*$ \\
CREAK (TE) * DURATION (TE) & -0.220 & .80 & 0.208 & -1.058 & 0.2900 & \\
DURATION (KE) * ONSET (VOICED) & -0.605 & .55 & 0.171 & -3.549 & 0.0004 & $* * *$ \\
DURATION (TE) * ONSET (VOICED) & 0.543 & 1.72 & 0.170 & 3.199 & 0.0014 & $* *$ \\
\hline
\end{tabular}

\footnotetext{
${ }^{2}$ Including an interaction CREAK*ONSET in the model was not justified by the predictions, although we note that doing so produced a model whose contribution fell just short of significance $\left(\chi^{2}=5.964, \mathrm{df}=2, \mathrm{p}=.051\right)$. Adding the three-way interaction ONSET*DURATION*CREAK did not significantly improve goodness of fit $\left(\chi^{2}=7.173, \mathrm{df}=4\right.$, $\mathrm{p}=.127$ ). The contents of models are specified in Appendix B.
} 
[Insert Figure 10 about here.]

The fixed effect of ONSET was not significant, meaning that the long-last grouping bias was found regardless of consonant voicing. However, the values associated with the interaction terms Duration (Ke) * Onset (VOICED) and Duration (TE) * Onset (VOICED) in Table 8 reveal that duration effects were significantly different in the voiced condition than in the baseline voiceless condition. To test for significant differences between conditions in which consonant class and duration were varied, pairwise comparisons were made using the lsmeans function in R (Tukey method with a .95 confidence interval). The results shown in Table 9 (a) - (d) indicate that all conditions in which there was a duration disparity were significantly different from the baseline control condition, regardless of consonant fortition or place. The OR associated with Table 9 (e) indicates that the odds a TeKe response were 1.58 higher when kee was long (representing a te.kee grouping) than when gee was long (representing a de.gee grouping). Table 9 (f) indicates that a $\mathrm{TeKe}$ response was $50 \%$ less likely $(\mathrm{OR}=.50)$ when tee was long (a tee.ke grouping), compared with when dee was long (a dee.ge grouping). These outcomes, which are evident in Figure 10a, indicate that DURATION effects were strongest in sequences with voiceless consonants.

Table 9. Pairwise comparisons for ONSET*DURATION.

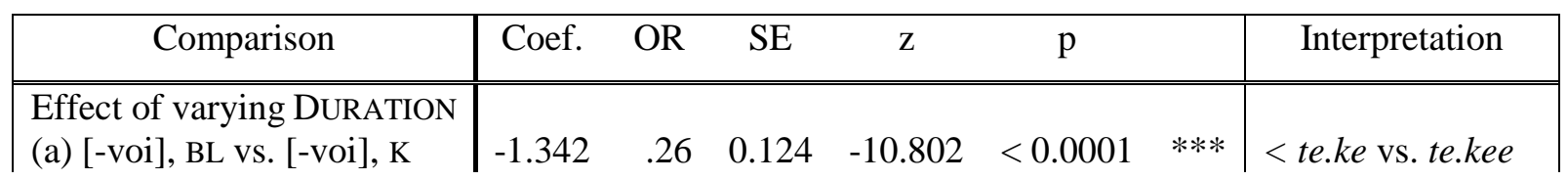




\begin{tabular}{l|rrrrrr|l|} 
(b) [-voi], BL vs. [-voi], T & 1.384 & 3.99 & 0.125 & 11.058 & $<0.0001$ & $* * *$ & $>$ te.ke vs. tee.ke \\
(c) [+voi], BL vs. [+voi], K & -0.736 & .48 & 0.117 & -6.290 & $<0.0001$ & $* * *$ & $<$ de.ge vs. de.gee \\
(d) [+voi], BL vs. [+voi], T & 0.841 & 2.32 & 0.115 & 7.324 & $<0.0001$ & $* * *$ & $>$ de.ge vs. dee.ge \\
\hline $\begin{array}{l}\text { Effect of varying ONSET } \\
\text { (e) [-voi], K vs. [+voi], K }\end{array}$ & 0.455 & 1.58 & 0.129 & 3.527 & 0.0056 & $* *$ & $>$ \\
(f) [-voi], T vs. [+voi], T & -0.693 & .50 & 0.128 & -5.414 & $<0.0001$ & $* * *$ & < tee.ke vs. de.gee \\
\end{tabular}

Key: $\mathrm{BL}=$ baseline duration (no disparity); $\mathrm{T}, \mathrm{K}$ indicate whether the coronal or velar syllable was longer in conditions with a length disparity. Voiceless and voiced are abbreviated as [-voi] and [+voi].

Turning to laryngealisation, Table 8 reveals that at baseline DURATION and ONSET, the fixed effect of CREAK was significant for velar syllables and approached significance for coronal syllables. The values associated with the $\operatorname{CREAK}(\mathrm{KE})$ term indicates that when laryngealisation was varied singly, the odds of a TeKe response were $26 \%$ lower, when a velar syllable was laryngealised $(\mathrm{OR}=.74)$, as compared with the baseline control sequences, and that this difference was significant $(\mathrm{p}=.0301)$. Odds of a TeKe response were $27 \%$ higher when a coronal syllable was laryngealised $(\mathrm{OR}=1.27)$ than in the baseline control condition; this outcome approached significance (CREAK(TE), p = .0764). Both outcomes are consistent with a laryngealised-modal grouping bias. The graph in Figure 10b, plotted from the response data for the singly-varied laryngealisation condition in Table 5b (Appendix A), shows that this tendency applied to all but the voiceless laryngealised syllable te. This asymmetry has no theoretical explanation, and we assume that the difference associated with te reflects idiosyncratic properties of the sequences that contained it.

The values associated with the interactions CREAK(TE) * Duration(Ke) and Creak(Ke) * DuRATION(TE) in Table 8 indicate that in the Opposed condition, effects of DURATION were significantly different when the short syllable was laryngealised than at baseline CREAK. The proportion of $\mathrm{TeKe}$ responses when duration was varied singly (baseline CREAK) is represented by the dark, middle columns in the histograms in Figure 11. The proportion of TeKe responses in the Opposed condition are represented by the adjacent columns to the right. Figures 11a and 11b show a high proportion of TeKe responses at baseline CREAK when the velar syllable was longer (Duration only columns, labelled teke:/dege:). However, when the short syllable was laryngealised, the propotion of TeKe responses was lower (columns labelled teke:/dege:). Statistically, at DURATION(KE), the odds of a TeKe response were 25\% lower when the coronal syllable was laryngealised than when it was modal. This statistic is the product of the OR of 
CREAK(TE) $(=1.27)$ and the OR of the interaction CREAK(TE)*DuRAtion(Ke) $(=.59) .1 .27 *$ $.59=.75$.The parallel pattern was observed in Figures 11c and 11d: when the coronal syllable was longer, the proportion of TeKe responses was low in the baseline CREAK condition (columns te:ke/de:ge). However, it was not quite as low when the shorter, velar syllable was laryngealised (columns te:ke/de:ge). Statistically, at DURATION(TE), a TeKe response were 1.21 times more likely when the velar syllable was laryngealised than when it was modal (the product of the OR of CREAK(KE), .74) and the OR of CREAK(KE)*Duration(TE), 1.64). In other words, Duration had a significantly stronger effect at baseline CREAK than when the shorter syllable was laryngealised in the Opposed condition. While inspection of Figure 11 confirms that outcomes in the Opposed condition were consistent across consonant class (fortition and place), pairwise comparisons indicated that differences between the columns representing the Duration and Opposed conditions in Figures 11a-d were not significant.

Finally, adding creak to the long syllable in the Overlapped condition did not produce consistent effects. Figures $11 \mathrm{c}$ and $11 \mathrm{~d}$ and the raw data in Tables 5 and 7 indicate that when the coronal syllable was longer, adding creak had no effect, compared with the outcome in the baseline CREAK, Duration condition. Figures $11 \mathrm{a}$ and $11 \mathrm{~b}$ indicate that when the velar syllable was longer, the effect of adding creak was inconsistent.

\section{[Insert Figure 11 about here.]}

\subsection{Discussion}

\subsubsection{The findings and connections to the literature}

At the outset of the study we wondered whether, in segmenting duration-varied sequences, our Zapotec-speaking participants would behave as predicted if they were interpreting increased duration as a cue to finality or alternatively, to stress. We found evidence of a robust long-last RGB in all conditions where duration was varied, both singly and co-varied with laryngealisation. This bias was consistent with the end-based segmentation hypothesis in (1), and suggests that listeners were interpreting increased vowel length as a cue signaling finality. Our participants did not respond as though they had adopted a stress-based segmentation strategy; in that case, as hypothesized in (3), we expected to find a long-first bias for sequences containing voiced stops. 
Although voiced and voiceless stop onsets were not associated with different grouping preferences, stop voicing mattered in that the proportion of long-last groupings was significantly higher for sequences containing voiceless stops. We think that this in unlikely to be due to differences in stop voicing, per se. An explanation that is consistent with the rhythmic grouping literature relates to differences in the disparity between long and short vowels that were necessary to produce naturalistic Zapotec-sounding sequences. In the voiced onset condition, long vowels were approximately $100 \mathrm{~ms}$ longer than the short vowels, while in the voiceless onset condition, the disparity was closer to $120 \mathrm{~ms}$. Prior rhythmic grouping studies has found that the strength of a grouping bias varies with the magnitude of the disparity between alternating sounds (Hay and Diehl 2007, Bhatara et al 2013, Crowhurst and Teodocio 2014). The pattern observed in our data is consistent with these earlier reports.

Where phonation was varied, we hoped to discover evidence bearing on whether our participants' grouping decisions were influenced by knowledge relating to the lexical and phonological distribution of laryngealised vowels, or rather to their surface phonetic properties. When phonation was varied singly, we observed a laryngeal-first RGB, consistent with the phonetic laryngeal segmentation hypothesis in (2). This bias was significant, though not as robust as the grouping bias associated with duration. We interpret the finding of a laryngeal-first RGB as indicating that listeners' grouping choices were influenced by their knowledge of acoustic properties of checked vowels in phrase-internal positions. The short laryngealised vowels used in the singly-varied sequences were prepared from tokens of checked vowels (the more common laryngealised vowel category) in the natural speech we initially recorded for our stimulus materials. These had the properties of nonfinal checked vowels in that they lacked the vowel-final glottal closure that is typical of phrase-final checked vowels. If participants' responses had been more influenced by their knowledge of the lexical distribution of laryngealised vowels and phonological patterns of phrase-internal delaryngealisation, we expected to find a laryngeal-last grouping pattern, predicted by the end-based segmentation strategy in (1).

A long-last RGB was observed in the co-varied conditions, regardless of how duration was varied with phonation, indicating that varied duration was a more robust cue to rhythmic 

interesting finding in the co-varied conditions was a significant interaction between duration and phonation in the Opposed condition. Although as noted, the general outcome in the Opposed condition was a long-last RGB, the proportion of long-last groupings was consistently lower in this condition than when duration was varied singly, and this difference was significant. In other words, in duration-varied sequences, replacing a short modal with a short laryngeal syllable decreased long-last groupings and increased laryngeal-last groupings. The response pattern we observed can be interpreted as being consistent with our end-based segmentation hypothesis but it did not seem to be congruent with the laryngeal-last grouping bias observed in the singlyvaried Laryngeal condition. This underscores the point made by Crowhurst and Teodocio Olivares (2014) that varying features separately vs. together can produce different percepts. In this case, we tentatively suggest that varying a long modal and a short laryngealised syllable could have produced a percept approximating that of a bisyllabic word with penultimate stress and a final checked vowel. Figure 12 presents two tokens of the word labada' 'gourd' in addition to the token in Figure $3 \mathrm{~b}$. This item is useful because it contains three low vowels separated by consonants of the same class (lenis stops). While there is natural variation, these tokens illustrate a tendency for final, checked vowels to be shorter, than penultimate modal vowels. This is particularly true when the periodically voiced (if any) portions of laryngealised vowels are compared with those of preceding modal vowels. In these tokens, the length of the penultimate vowel is slightly greater as it is a stressed vowel before a voiced stop. However, the same pattern can be seen in yeche' 'thorn' in Figure $2 \mathrm{a}$, in which the consonant separating the mid vowels is voiceless. In this case, the checked vowel /e'/ is proportionally shorter than it would be in phrase-final position. While this tentative explanation is based on our informal observations, quantitative support requires a controlled study of duration patterns of vowels in Betaza Zapotec; such a study would be an important next step.

This outcome in the Opposed condition was also interesting because it suggests that duration interacted differently with laryngealisation in the group of Zapotec speakers we studied than with intensity in a group of participants from the same community studied by Crowhurst and Teodocio Olivares (2014). In that study, intensity was a stronger predictor of responses than duration. The two studies with Betaza Zapotec speakers allow us to observe that listeners' 
responses to periodically fluctuating features in a subjective grouping study seem to depend on whether they are varied singly, or together with another feature as well as the particular combination of features. A comparison of these studies is meaningful as the design and testing procedures were parallel. Taken together, they suggest that varied intensity, duration, and laryngealised phonation as predictors of response can be placed on a continuum of influence, with laryngealised phonation on the low end, intensity on the end, and duration intermediate between the two. One lesson from these studies is that we should be cautious in relating listeners' use of information about acoustic features varied singly in rhythmic segmentation tasks to how they may use the same feature in segmenting speech. Varying acoustic features singly in rhythmic grouping studies is artificial, given that actual speech is multidimensional.

\subsubsection{Limitations, unanswered questions, and future directions}

In the Overlapped condition, in which a long laryngealised vowel was alternated with a short modal vowel, we found no consistent differences with the duration-only condition. The outcomes in the singly-varied conditions produce the expectation that grouping cues from creaky phonation and duration should have worked against one another in the Overlapped condition. Given that the same syllable was both long and larygealised in this condition, we might have expected a lower proportion of long-last groupings. However, in retrospect, it is not clear that the difference between long and short laryngealised vowels in our stimulus set provided a fair test of the perception of length differences amongst laryngealised vowels, other factors being equal. Because the longer laryngealised vowels in our sequences were based on actual rearticulated vowels that our recorder had produced as the presumed long counterparts of short laryngealised vowels (checked vowels), there were likely markers of the category difference in addition to duration. For this reason, we do not believe that the results in the Overlapped condition provide information that contributes to our understanding of outcomes in the other conditions. The interesting findings of our study, therefore, are the outcome in the singly-varied phonation condition, and the results from the conditions in which a long modal syllable was combined with a short modal vs. short laryngealised syllable.

As indicated in $\S 3.1 .3$, all participants in our study were exposed to sequences containing voiced stops in a first, and to voiceless stop sequences in a second session on different days. This was done because the hypotheses in the two conditions was different: we expected to find (if 
anything) a long-last outcome in the voiceless condition, but in the voiced condition, we thought that either a long-last or long-first outcome might be possible. Ordering the sessions as we did was a design feature intended to preclude the possibility that exposure to the voiceless sequences might have a confounding effects on their decisions in the voiced condition. None of our hypotheses for varied phonation or interactions with duration were related to consonant voicing differences, and in the crucial conditions, it is clear that trends ran in the same directions. Therefore, we see no evidence that our results or their interpretation are compromised by the effects associated with the sequence in which subjects participated in the sessions. We cannot rule out the possibility that the stronger long-last RGB associated with the voiceless stop condition might have been an order effect, but we consider the explanation offered in $\S 3.3 .1$ to be reasonable, and note this outcome was not linked to our initial hypotheses.

A final concern relates to a possible relationship between laryngealised phonation and pitch. All Zapotec languages are tone language, and in $\$ 2$ we noted that laryngealised vowels participate fully in the set of tonal contrasts in Betaza Zapotec. However, the pitch tracks shown in the spectrograms in Figures $3-7$ show the effects of fo damping especially during the creaky portions of laryngealised vowels. We do not know how these effects might have influenced participants' perception of pitch and how this might have influenced their grouping decisions.

A question that remains unanswered relates to differences in the findings for duration varied singly among our participants and in a comparable group of Zapotec speaking participants studied by Crowhurst and Teodocio Olivares (2014). As noted in §1.2.3.1, Crowhurst and Teodocio report a long-first RGB when they were tasked with segmenting streams of syllables in which duration was varied singly. This finding was notable as it differed from long-last RGBs found with speakers of other languages tested (see citations in §1.2.3.1). Crowhurst and Teodocio Olivares' stimulus materials included only syllables beginning with voiced (lenis) stops and as stressed vowels are lengthened before lenis consonants in Betaza Zapotec, Crowhurst and Teodocio Olivares considered the possibility that listeners might have tended to segment alternating sequences into units resembling trochaic feet, consistent with the stress pattern. However, this explanation was not fully convincing since in a co-varied condition in which a long loud syllable was alternated with a short soft one, Crowhurst and Teodocio Olivares found that increasing the magnitude of the duration disparity increased long-last 

phonological pattern of final lengthening in Betaza Zapotec, and see no connection with language-specific stress patterning.

In light of our findings, combined with results Crowhurst and Teodocio Olivares report in their co-varied conditions, a different explanation for the long-short grouping bias in their singlyvaried duration seems possible. As a result of the way in which the auditory system sums intensity over time, humans perceive longer sounds as being louder than short sounds of the same intensity. Although Crowhurst and Teodocio Olivares controlled for mean level intensity, it may be that the long-short grouping bias they report reflected a perception of varying intensity. We tentatively suggest that a reason this might have posed a special problem in Crowhurst and Teodocio Olivares' study was that listeners could have been especially inclined to perceive intensity differences given that intensity was one of the features varied in the study. This was not the case in our study, and we state once again that the cumulative results of these studies suggest that the context in which listeners are presented with variations in acoustic feature clearly (and unsurprisingly) seems to affect their overall impressions. However, to control for unwanted effects that might relate to perceived loudness, future studies of the effect of varied duration on subjective grouping preferences should combine duration-varied syllables that listeners have rated as being of equivalent loudness in a discrimination study.

Finally, our finding of a laryngeal-first grouping bias among Zapotec-speaking listeners stands in contrast to a preference for modal-creaky pairings reported by Kelly et al (2014) in a study with American English speakers in which creaky phonation and duration were varied, as they were in the present study. However, it would be preliminary to conclude that this grouping preference difference is the result of linguistic experience given that the way in which laryngealisation was manipulated also differed between these experiments. In Kelly et al (2014), creaky phonation was synthesised by reducing pitch at regular intervals at the end of the vowel. In the current study, naturally produced syllables were used. To better understand the ways in which language differences may affect listeners' perceptions of varied phonation, future studies could usefully directly test speakers of different languages using parallel sound sequences in which phonation is varied. 


\section{Concluding remarks}

Returning to our point of departure, the set of issues we find particularly interesting in the rhythmic grouping literature pertain to the question of whether rhythmic grouping preferences in humans reflect innate perceptual predispositions, or whether they are learned. As discussed in $\S 1$, a much replicated loud-first RGB in humans may be universal, and while pitch-based RGBs have varied across studies, there is evidence that the ability to segment pitch-varied sequences is not uniquely human. On the other hand, there is ample evidence from studies reviewed in $\S 1$ to suggest that duration-based RGBs have a learned component and are sensitive to language input. Our research was conducted under the premise that if any human RGBs are sensitive to linguistic background, then it should be possible to elicit RGBs based on phonologically important features other than those studies in prior research, and to show that these biases can be connected to language-specific patterns. The present study contributes to this effort by demonstrating a preference for laryngeal-modal syllable groupings among native speakers of Zapotec, for whom vowel laryngealisation is a contrastive linguistic feature. We have also made a case for associating this grouping bias with language-specific phonetic patterns. The current research studied in addition the effect of varying vowel duration with and without phonation, and contributes additional evidence that duration-based RGBs are not only learned, but are also highly sensitive to the phonetic context in which varied duration is presented in rhythmic grouping experiments. A number of rhythmic grouping studies have studied varied intensity and duration as acoustic features that participate in prosodic patterns related to the stress contrast and to penultimate lengthening. Phonation differences can be related to prosody in similar ways: breathy as well as creaky phonation can signal constituent endings, and creaky phonation can be associated with the stress contrast, as in Mixtec languages (e.g. Gerfen 1999). We anticipate that future studies investigating the influence of varying such linguistic features on RGBs can be fruitful, and further suggest that experiments with speakers of less studied, especially non-IndoEuropean languages, should be a priority.

\section{Acknowledgements}

The current research was funded by National Science Foundation grant BCS-1147959 awarded to the University of Texas at Austin for Megan Crowhurst. 


\section{References}

Avelino, H. (2001). The phonetic correlates of fortis/lenis in Yalálag Zapotec consonants. MA thesis, University of California at Los Angeles.

Avelino, H. (2004). Topics in Yalálag Zapotec, with Particular Reference to its Phonetic Structures. PhD dissertation, University of California at Los Angeles.

Bates D, \& Maechler M. (2013). Matrix: Sparse and Dense Matrix Classes and Methods. URL http://CRAN.R-project.org/package=Matrix. R package version 1.0-12. [p181]

Beckman, M. E., \& Edwards, J. (1990). Lengthenings and shortenings and the nature of prosodic constituency. In J. Kingston and M. Beckman (Eds.), Papers in Laboratory Phonology I (pp. 179-200). Cambridge University Press.

Beckman, M. E., \& Venditti, J. J. (2010). Tone and intonation. The Handbook of Phonetic Sciences $\left(2^{\text {nd }}\right.$ ed.). W. J. Hardcastle, J. Laver, and F. E. Gibbon (eds.) Blackwell Handbooks in Linguistics (pp. 603-652). UK: Wiley-Blackwell.

Bhatara, A., Boll-Avetisyan, N., Unger, A., Nazzi, T., \& Höhle, B. (2013). Native language and stimulus complexity affect rhythmic grouping of speech. Journal of the Acoustical Society of America, 134, 3828-3843.

Bion, R. A. H., Benavides-Varela, S., \& Nespor, M. (2011). Acoustic markers of prominence influence infants' and adults' segmentation of speech sequences. Language and Speech 54, 123140.

Boersma, P., \& Weenink, D. (2013). Praat: doing phonetics by computer [Computer program]. Version 5.3.03. http://www.praat.org/.

Bolton, T. (1894). Rhythm., American Journal of Psychology 6, 145-238.

Byrd, D. (2000). Articulatory Vowel Lengthening and Coordination at Phrasal Junctures. Phonetica, 57:3-16.

Cambier-Langeveld, T., Nespor, M., \& van Heuven, V. J. (1997). The domain of final lengthening in production and perception in Dutch. In EUROSPEECH. (Accessed 17 March 2016 at

http://www.mirlab.org/conference_papers/International_Conference/Eurospeech\%201997/pdf/t4 b/a0559.pdf)

Carlson, R., Hirschberg, J., \& Swerts, M. (2005). Cues to upcoming Swedish prosodic boundaries: Subjective judgment studies and acoustic correlates. Speech communication, 46(3), 326-333. 
Crowhurst, M. J. (2015). Iambic-Trochaic Law effects and the subjective grouping preferences of English and Spanish speakers. In submission, Laboratory Phonology.

Crowhurst, M. J., \& Teodocio Olivares, A. (2014). The joint influence of duration and intensity on the subjective grouping of rhythmic speech among Zapotec and English speakers. Phonology, $31,1-44$.

Dilley, L., Shattuck-Hufnagel, S., \& Ostendorf, M. (1996). Glottalisation of word-initial vowels as a function of prosodic structure. Journal of Phonetics, 24:423-444.

D'Imperio, M., \& Michelas, A. (2010). Embedded register levels and prosodic phrasing in French. In Speech Prosody. URL http://speechprosody2010.illinois.edu/papers/100879.pdf. Accessed 1 April 2016.

Fant, G., \& Kruckenberg, A. (1989). Preliminaries to the study of Swedish prose reading and reading style. STL-QPSR, 2(1989), 1-83.

Fletcher, J. (2010). The prosody of speech: timing and rhythm. The Handbook of Phonetic Sciences $\left(2^{\text {nd }}\right.$ ed.). W. J. Hardcastle, J. Laver, and F. E. Gibbon (eds.) Blackwell Handbooks in Linguistics (pp. 523-602). UK: Wiley-Blackwell.

Fraisse, P. (1982). Rhythm and tempo. The psychology of music, 1, 149-180.

Gerfen, H. (1999). Phonology and phonetics in Coatzospan Mixtec. Dordrecht: Kluwer Academic Publishers.

Gobl, C., \& Ní Chasaide, A. (2010) Voice Source Variation and Its Communicative Functions. The Handbook of Phonetic Sciences ( $2^{\text {nd }}$ ed.). W. J. Hardcastle, J. Laver, and F. E. Gibbon (eds.) Blackwell Handbooks in Linguistics (pp. 378-423). UK: Wiley-Blackwell.

Hay, J., \& Diehl, R. (2007). Perception of rhythmic grouping: Testing the iambic/trochaic law. Perception \& Psychophysics, 69, 113-122.

Hay, J. F., \& Saffran, J. R. (2012). Rhythmic grouping biases constrain infant statistical learning. Infancy, 17(6), 610-641.

Hayes, B. (1995). Metrical Stress Theory: Principles and Case Studies. Chicago: University of Chicago Press.

Henton, C., \& Bladon, R. A. W. (1988). Creak as a sociophonetic marker. Language, Speech and Mind: Studies in Honour of Victoria A. Fromkin. Routledge, London, and New York.

Hockey, B. A., \& Fagyal, Z. (1999). Phonemic length and pre-boundary lengthening: an experimental investigation on the use of durational cues in Hungarian. In 14th International Congress of Phonetic Sciences, Berkeley, University of California (pp. 313-316). 
Hosmer, D. W. Jr., \& Lemeshow, S. (2004). Applied logistic regression. John Wiley \& Sons.

Iversen, J. R., Patel. A. D., \& Ohgushi, K. (2008). Perception of rhythmic grouping depends on auditory experience. Journal of the Acoustical Society of America, 124, 2263-2271.

Jaeger, J. (1983). The fortis/lenis question: evidence from Zapotec and Jawañ. Journal of Phonetics, 11, 177-189.

Jaeger, J., \& van Valin, R. (1982). Initial consonant clusters in Yatee Zapotec. International Journal of American Linguistics, 48, 125-138.

Kelly, N., Crowhurst, M. J., \& Cobb, C. (2014). "The effect of duration and glottalisation on the perception of rhythm". In Herman Leung et al (eds.) Proceedings of the $40^{\text {th }}$ Annual Meeting of the Berkeley Linguistics Society (pp. 215-232). Berkeley Linguistics Society, Inc.

Kusumoto, K., \& Moreton, E. (1997). Native language determines parsing of nonlinguistic rhythmic stimuli. Journal of the Acoustical Society of America, 105, 3204.

Long, R., \& Cruz, S. (2000). Diccionario Zapoteco de San Bartolomé Zoogocho, Oaxaca. Serie de vocabularies y diccionarios indígenas "Mariano Silva y Aceves" 38. México. México: Instituto Lingüístico de Verano.

Molnar, M., Carreiras, M., \& Gervain, J. (2014). Language dominance shapes non-linguistic rhythmic grouping in bilinguals. Cognition.

Molnar, M., Lallier, M., \& Carreiras, M. (2014). The amount of language exposure determines nonlinguistic tone grouping biases in infants from a bilingual environment. Language Learning, 64(s2), 45-64.

de la Mora, D. M., Nespor, M., \& Toro, J. M. (2013). Do humans and nonhuman animals share the grouping principles of the iambic-trochaic law?. Attention, Perception, \& Psychophysics, $75(1), 92-100$.

Nakai, S., Kunnari, S., Turk, A., Suomi, K., \& Ylitalo, R. (2009). Utterance-final lengthening and quantity in Northern Finnish. Journal of phonetics, 37(1), 29-45.

Nellis, D., \& Hollenbach, B. (1980). Fortis versus lenis in Cajonos Zapotec phonology, International Journal of American Linguistics, 46, 92-105.

Patel, A. D. (2008). Music, language, and the brain. Oxford university press.

Pike, E. (1948). Problems in Zapotec tone analysis. International Journal of American Linguistics, 14, 161-170.

R Core Team (2013). R: A language and environment for statistical computing. R Foundation for Statistical Computing, Vienna, Austria. URL http://www.R-project.org/. 
Redi, L., \& Shattuck-Hufnagel, S. (2001). Variation in the realisation of glottalisation in normal speakers. Journal of Phonetics, 29, 407-429.

Remijsen, B., \& Gilley, L. (2008). Why are three-level vowel length systems rare? Insights from Dinka (Luanyjang dialect). Journal of Phonetics, 36(2), 318-344.

Rice, C. C. (1992). Binarity and ternarity in metrical theory: Parametric extensions. Unpublished doctoral dissertation, University of Texas, Austin.

Saffran, J. R., Newport, E. L., \& Aslin, R. N. (1996). Word segmentation: The role of distributional cues. Journal of Memory \& Language, 35, 606-621.

Sonnenschein, A. H. (2004). A descriptive grammar of San Bartolomé Zoogocho Zapotec. PhD dissertation, University of Southern California.

Teodocio-Olivares, A., \& Crowhurst, M.J. (2007a). Elicitation log: campo semantico "plantas". File: Plantas_Lupe_BZ20070607TC.xls. Date: June 28, 2007.

Teodocio-Olivares, A., \& Crowhurst, M.J. (2007b). Lupe_6-6-07.wav. Field recording of elicitation session for plant names in Betaza Zapotec. Date: June 8, 2007.

Turk, A. E., \& Shattuck-Hufnagel, S. (2000). Word-boundary-related duration patterns in English. Journal of Phonetics, 28(4), 397-440.

Vos, P. (1977). Temporal duration factors in the perception of auditory rhythmic patterns. Scientific Aesthetics/Sciences de l'Art, 1, 183-199.

Wightman, C. W., Shattuck-Hufnagel, S., Ostendorf, M., \& Price, P. J. (1992). Segmental durations in the vicinity of prosodic phrase boundaries. J. Acoust. Soc. Am., 91 (3),,1707-17.

Woodrow, H. (1909). A Quantitative Study of Rhythm: The effect of variations in intensity, rate, and duration. Columbia University Contributions to Philosophy and Psychology, Vol. XVIII, No. 1.

Woodrow, H. (1911). The role of pitch in rhythm. Psychological Review, 18(1), 54.

Woodrow, H. (1951). Time perception. In S. Stevens (ed.) Handbook of Experimental Psychology. J Wiley \& Sons, New York.

Yoshida, K. A., Iversen, J. R., Patel, A. D.,Mazuka, R., Nito, H., Gervain, J., \& Werker, J. F. (2010). The development of perceptual grouping biases in infancy: A Japanese-English crosslinguistic study. Cognition, 115, 356-361. 


\section{Figures}

Figure 1.

Laryngealised and delaryngealised tokens of checked /o'/ in nonfinal position.

Figure 2.

(a) Laryngealised [e'] and (b) delaryngealised token of checked /e'/ in nonfinal position.

Figure 3.

Phrase-final checked vowels.

Figure 4.

Canonical phrase-final rearticulated vowels.

Figure 5.

Variation in rearticulated vowels.

Figure 6.

Variably realised checked vowels.

Figure 7.

Variation in nonfinal checked vowels.

Figure 8.

Short laryngealised syllables used in stimuli.

Figure 9.

Velar laryngealised syllables used in stimuli

Figure 10.

Proportion of TeKe responses in the singly-varied Duration and Laryngeal conditions

Figure 11.

Proportion of TeKe responses in the control (white), Creak (mauve), Duration (salmon), Opposed (buff), and Overlapped (turquoise) conditions.

Figure 12.

Durational differences between penultimate stressed and final checked vowels. 
(a) beko' yo'o / beko' jo'o / 'coyote', larygealised [o']

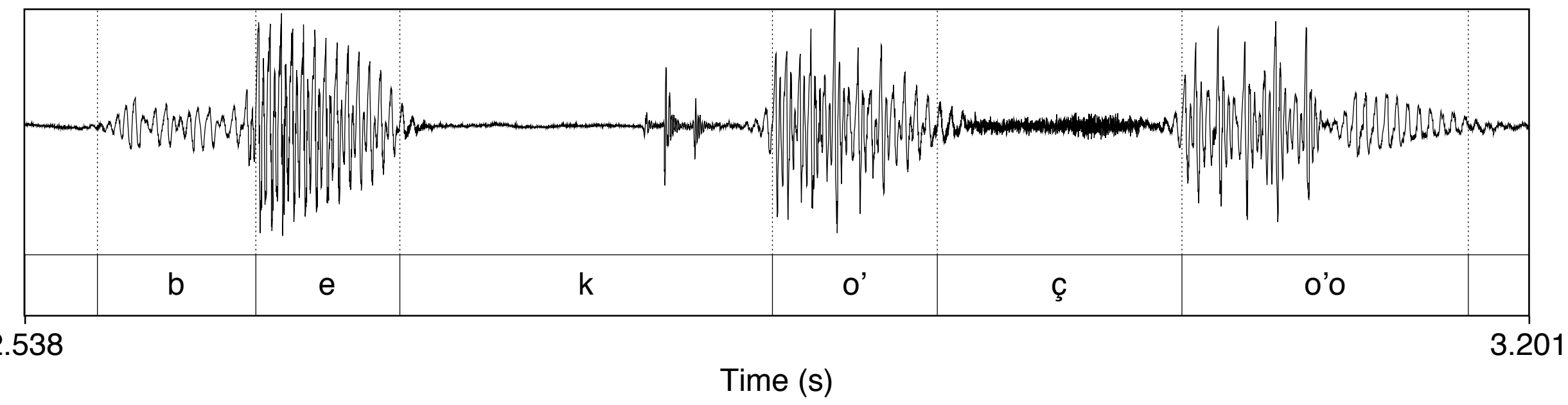

(b) beko' yo'o / beko' jo'o/ 'coyote', de-larygealised / o' / $\rightarrow$ [o']

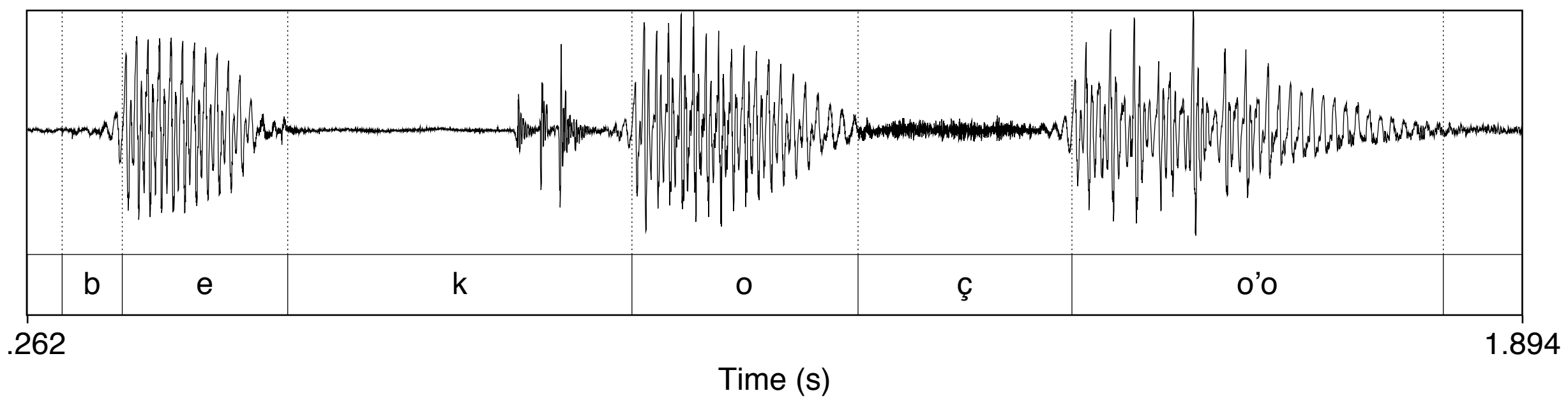

Fig. 1. Laryngealised and delaryngealised tokens of checked /o'/ in nonfinal position. 
(a) Laryngealised /e'/ in yeche' / jetfe'/ 'thorn'

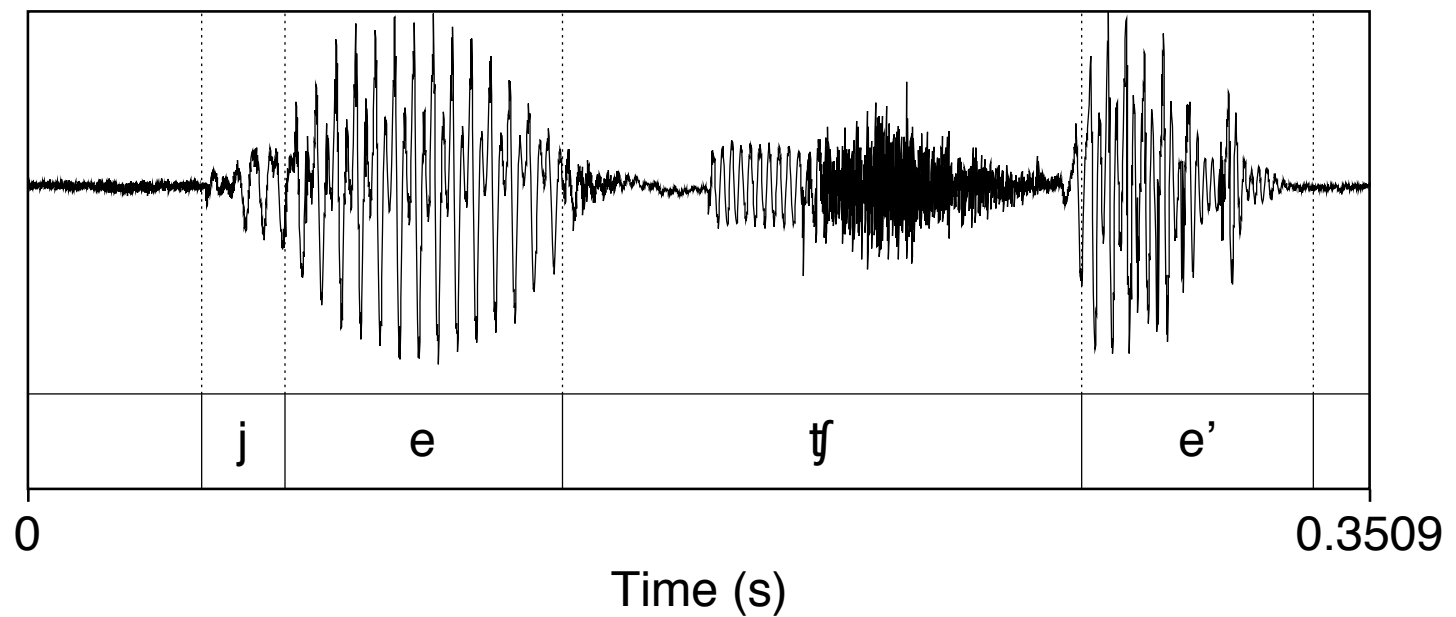

(b) De-laryngealised /e' / in yeche' bi'a / jetfe' bi'a/ 'thorn of the prickly pear cactus'

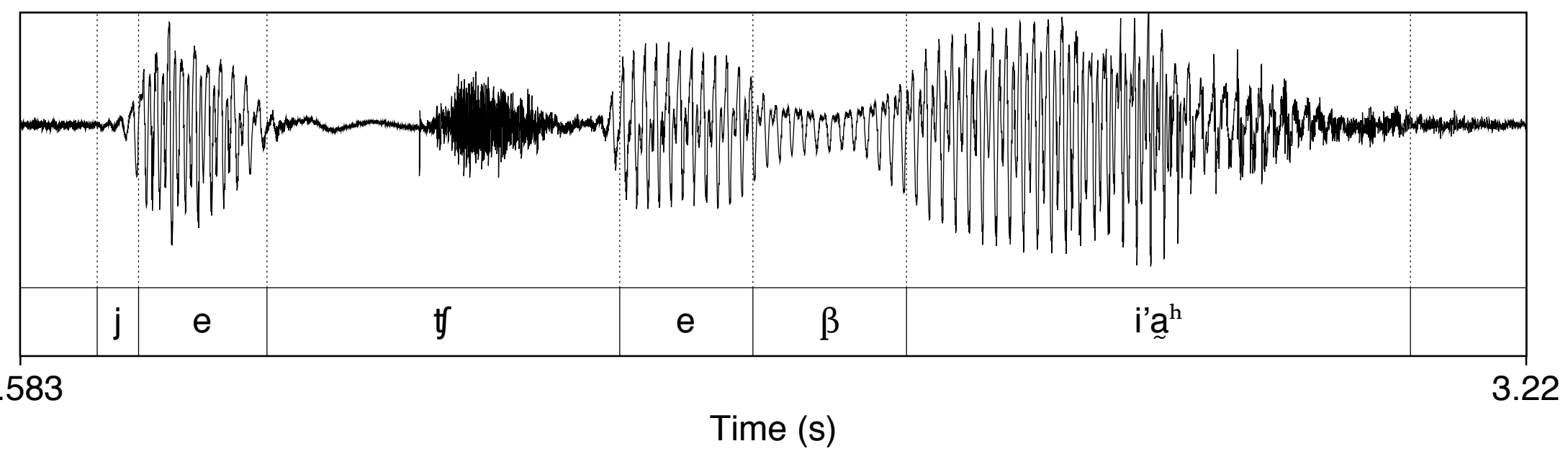

Fig. 2. (a) Laryngealised [e'] and (b) delaryngealised token of checked /e'/ in nonfinal position. 
(a) yinha' / jina'/ 'chile'

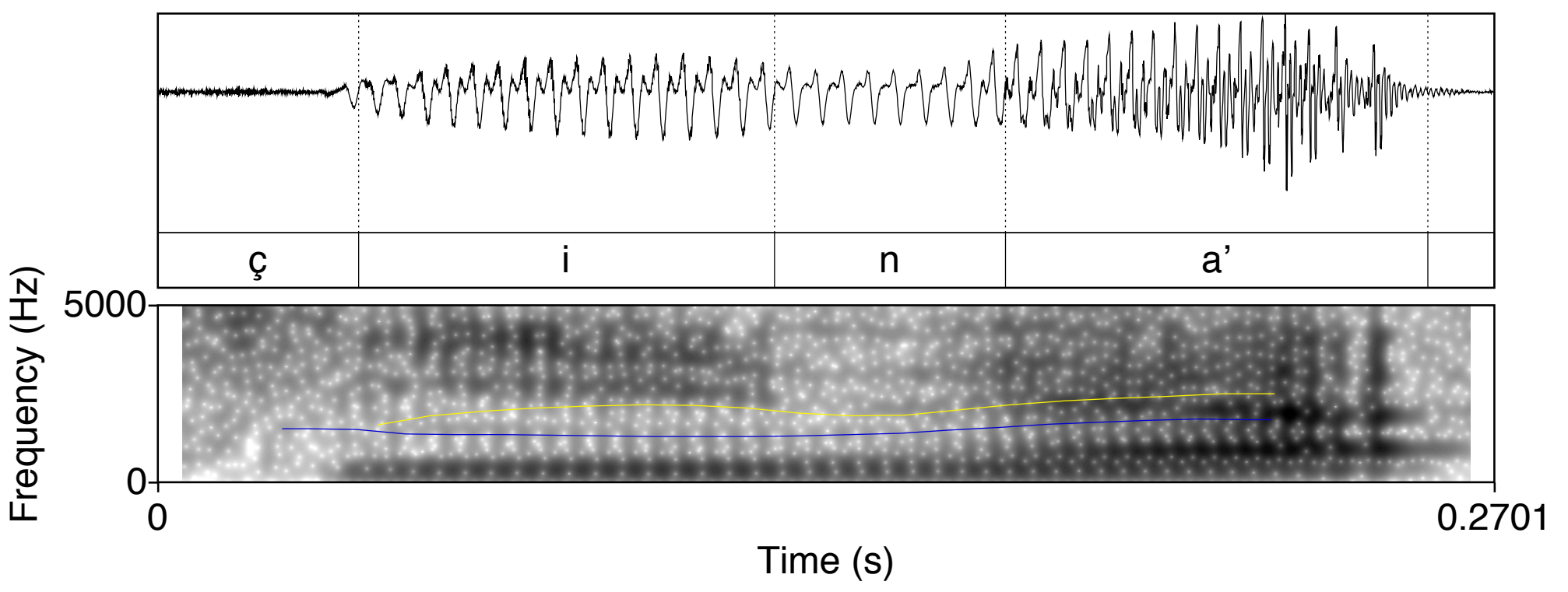

(b) labada' / labada' / 'gourd'

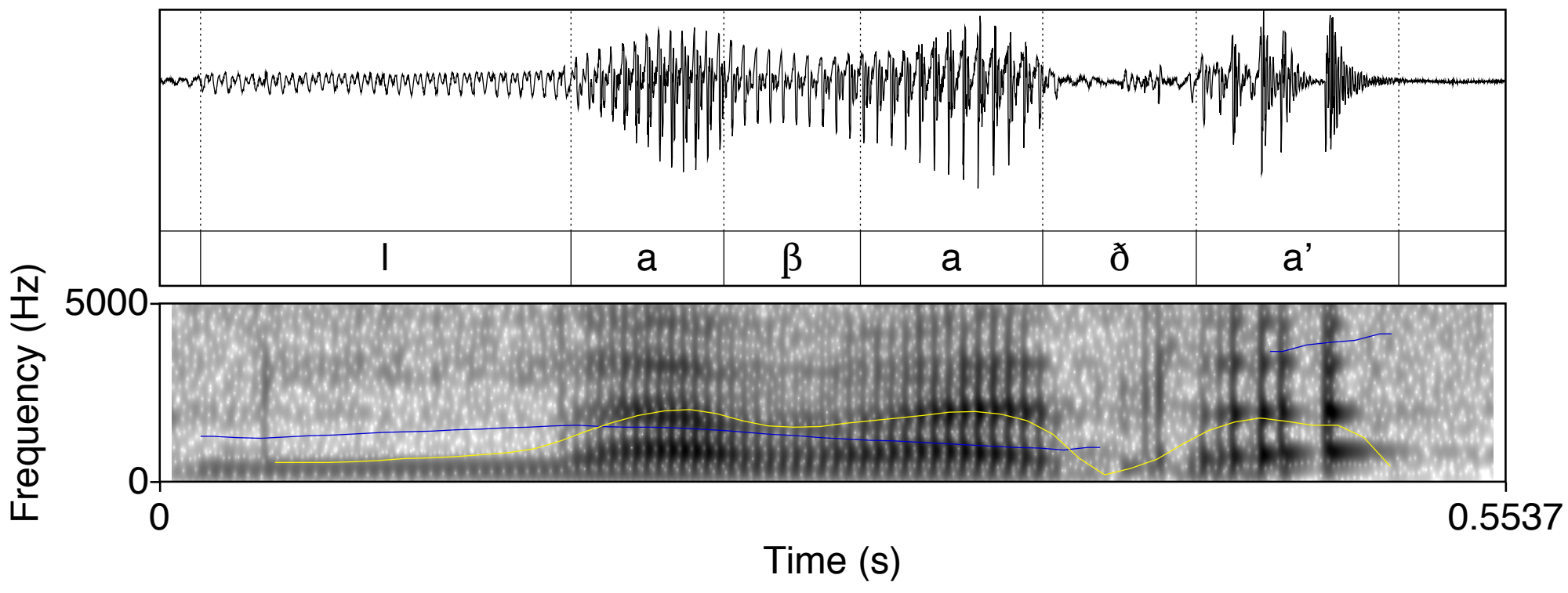

Fig. 3. Phrase-final checked vowels. 
(c) yixe' /jife'/ 'herb'

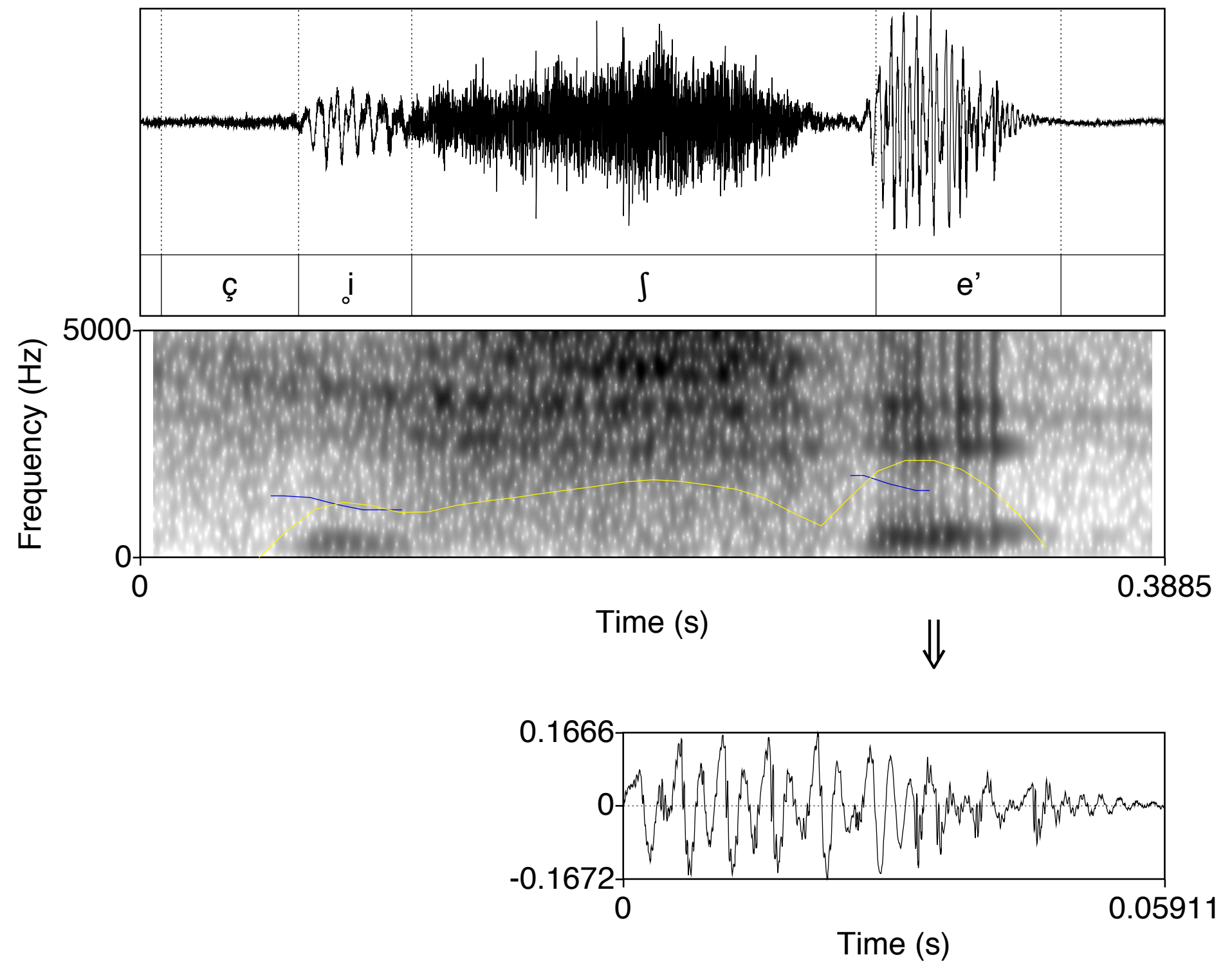

Fig. 3. Phrase-final checked vowels. 
(a) sla'a / sla'a / 'bitter'

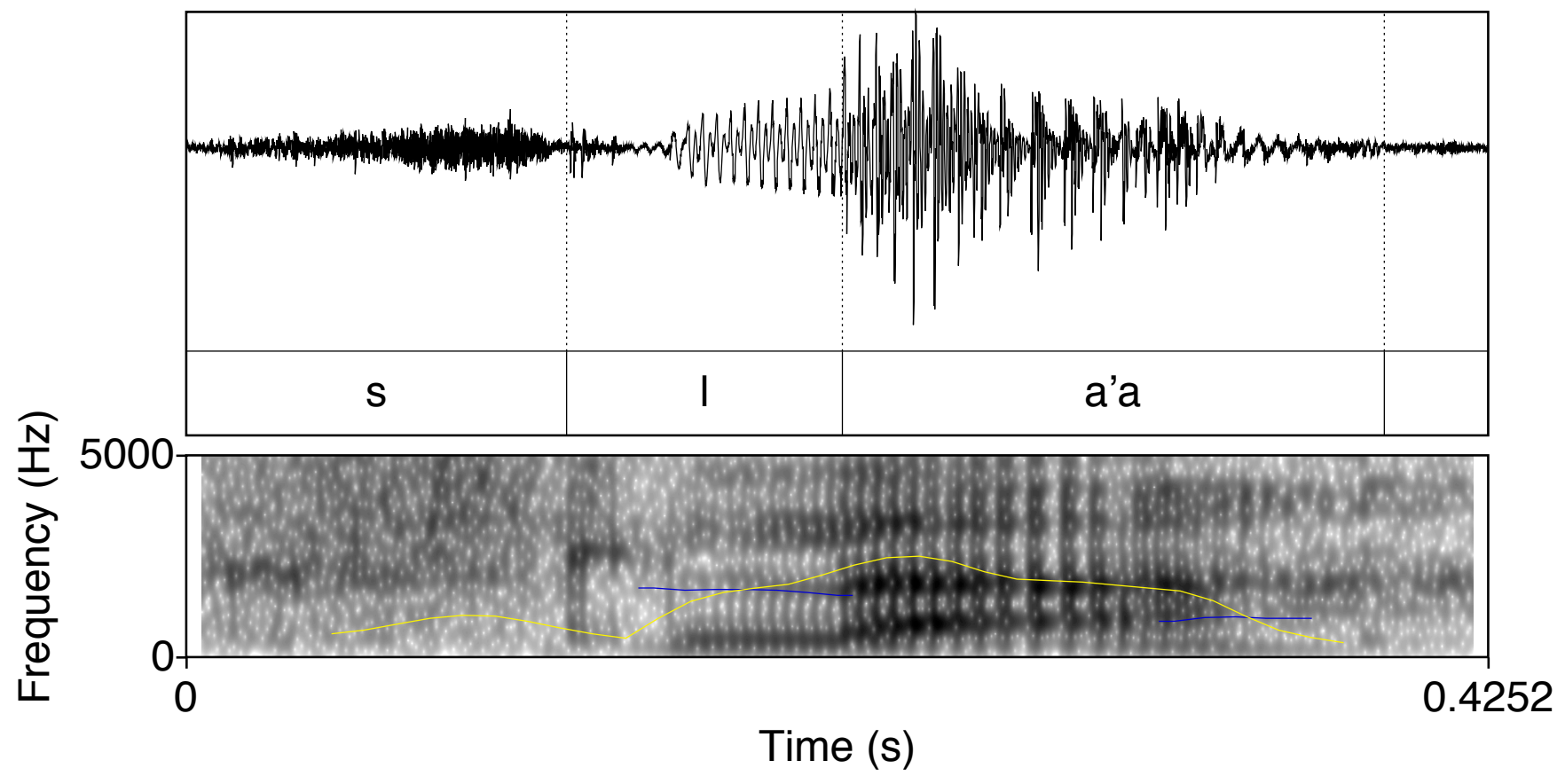

(b) bdze'e / bdze'e / 'ant'

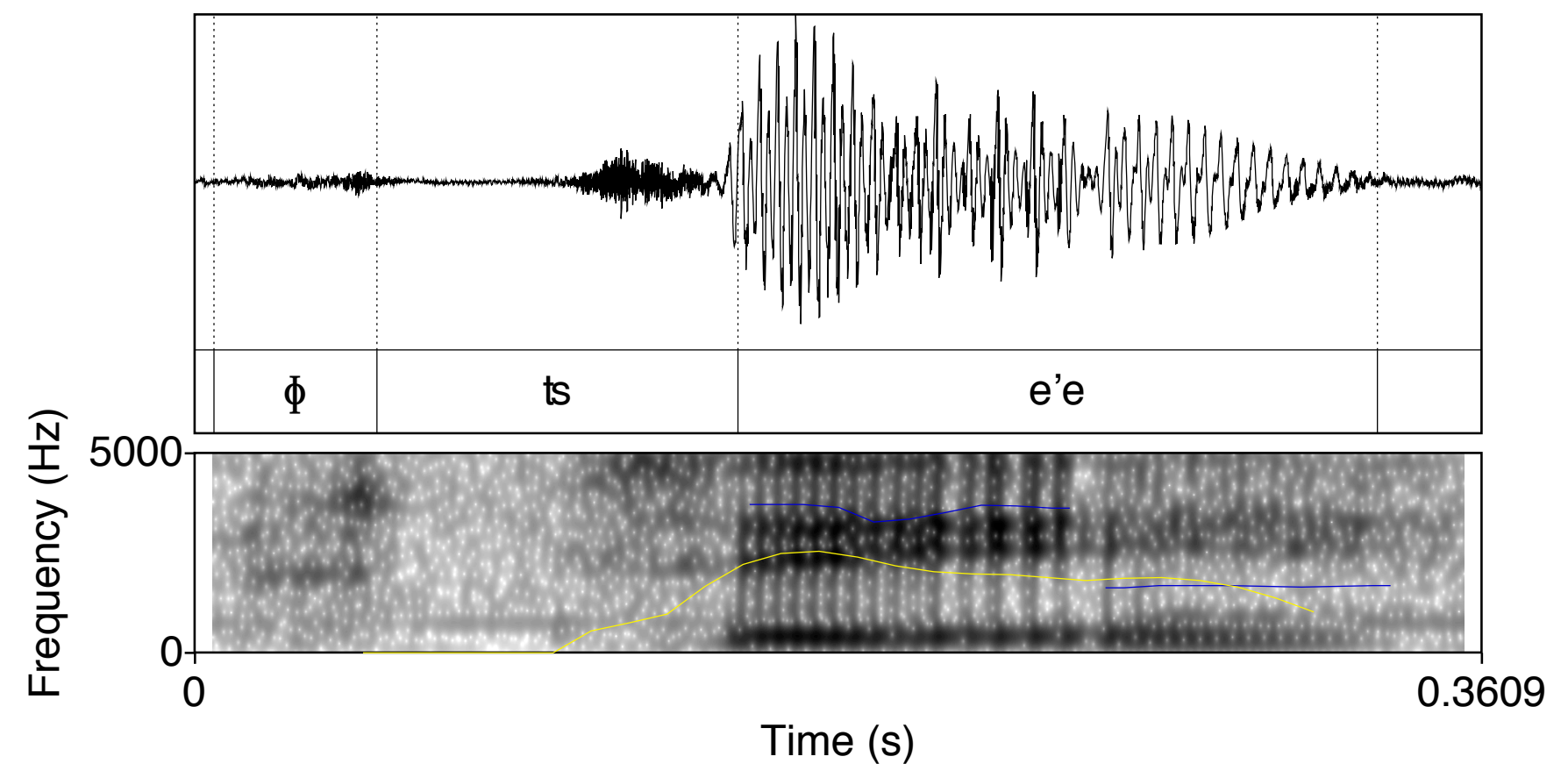

Fig. 4. Canonical phrase-final rearticulated vowels. 
(a) yinha' ya'a /jina' ja'a / 'green chile'

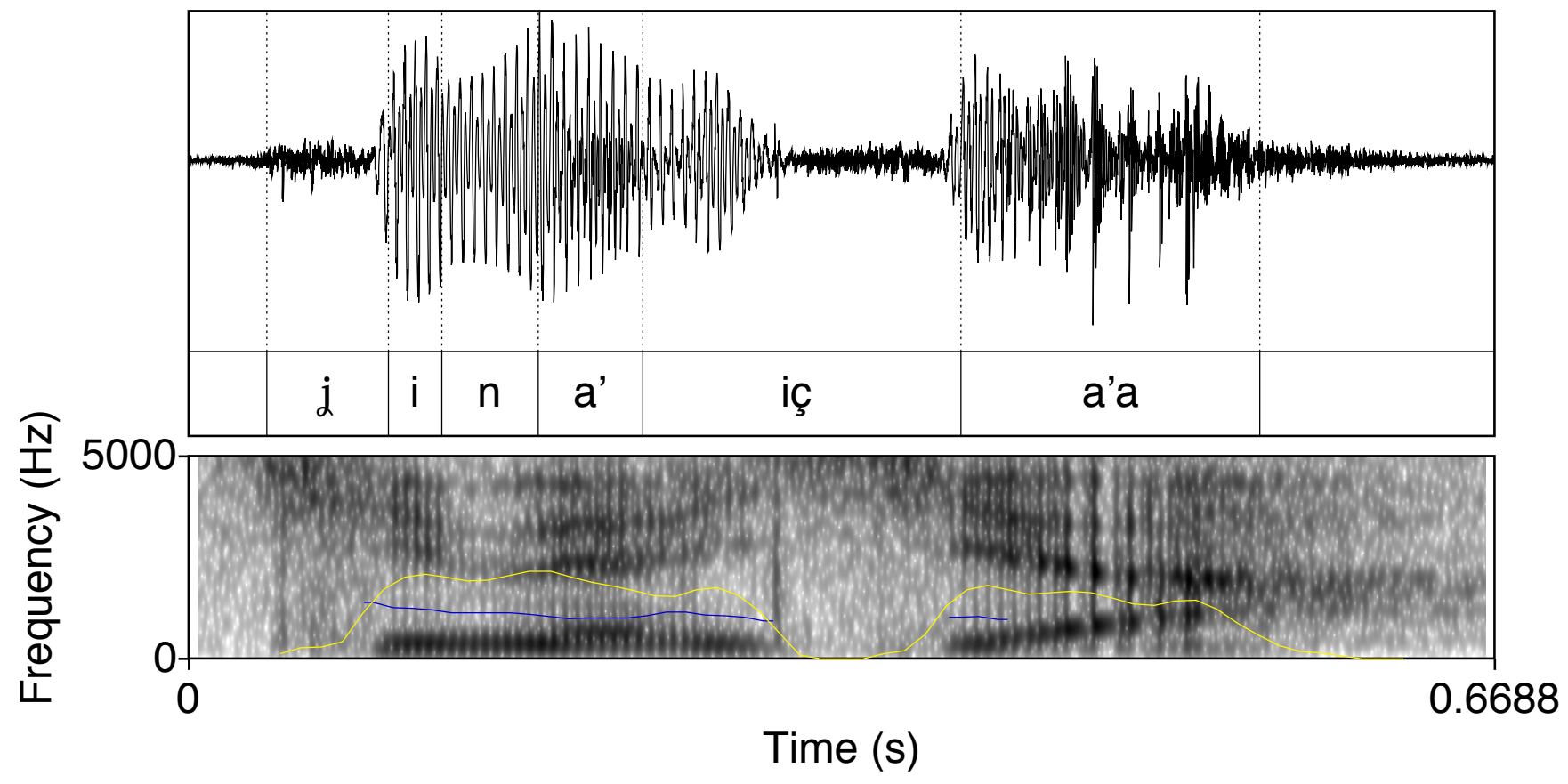

(b) yinha' ya'a /jina' ja'a / 'green chile' (token 2)

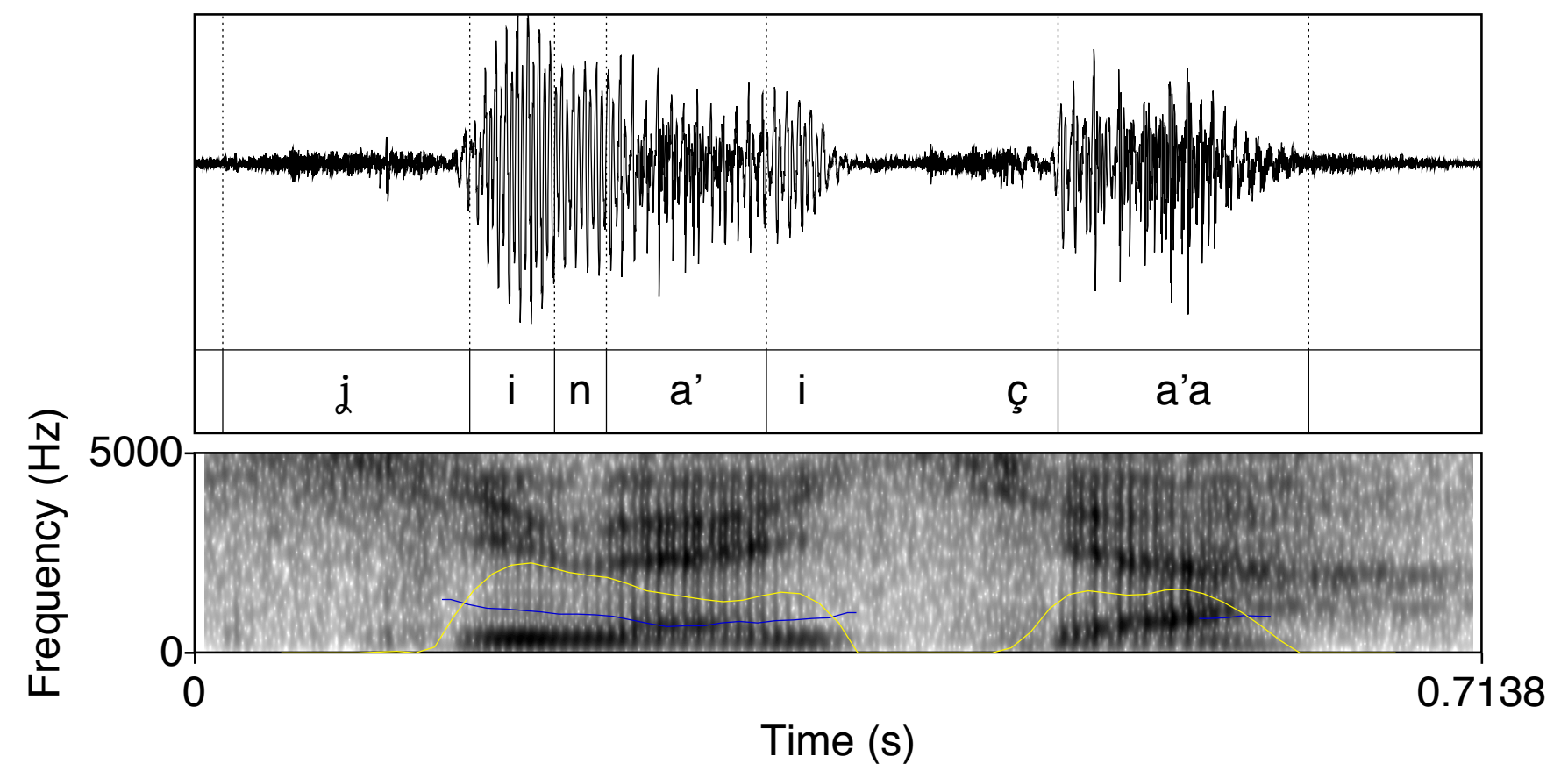

Fig. 5. Variation in rearticulated vowels. 
a) bi'abel xhinje / bi'abel zinвe / 'hallucinogenic mushroom sp.'
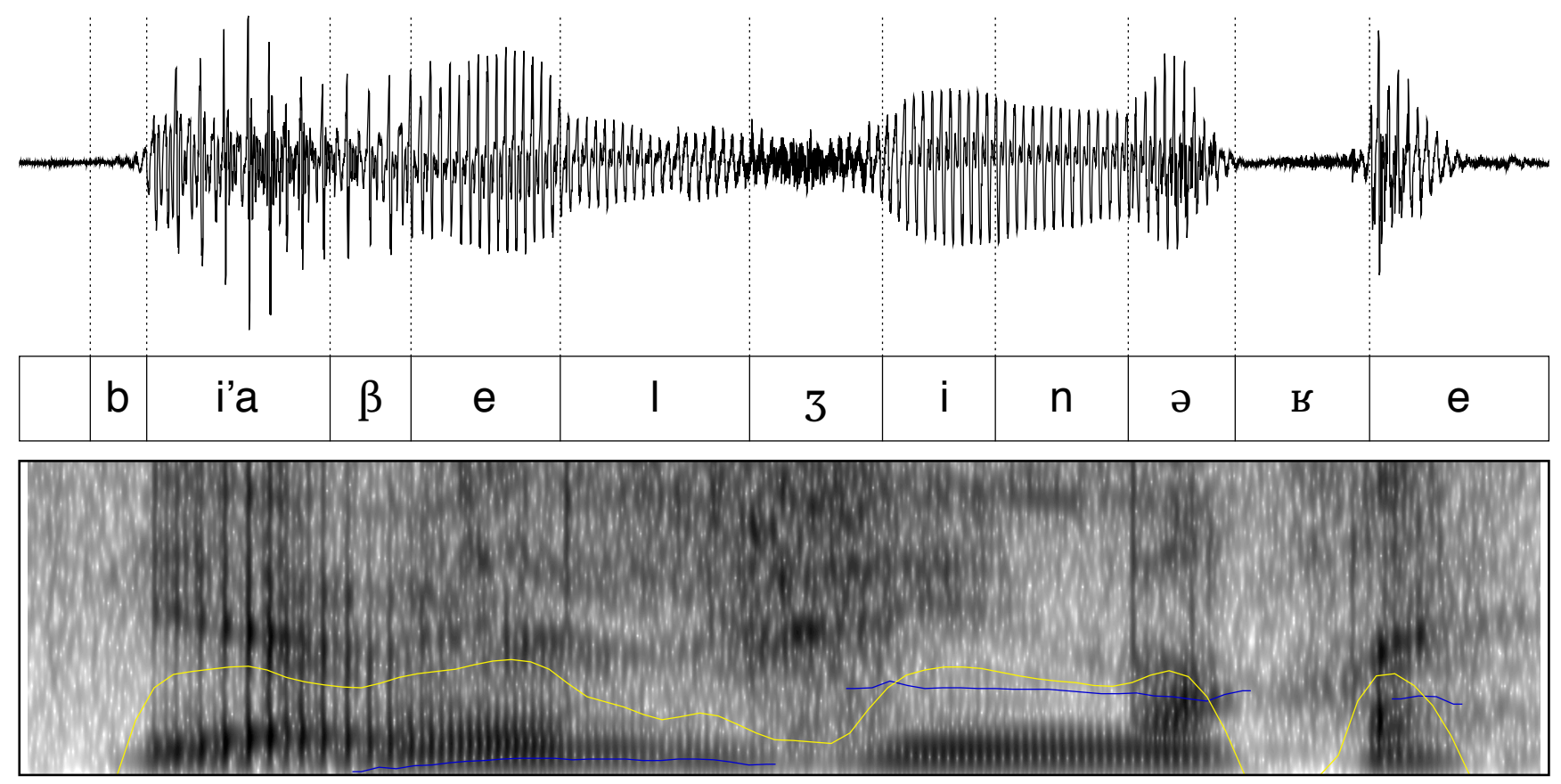

b) yag yixe' dao' / jag jife' dao' / 'bush'
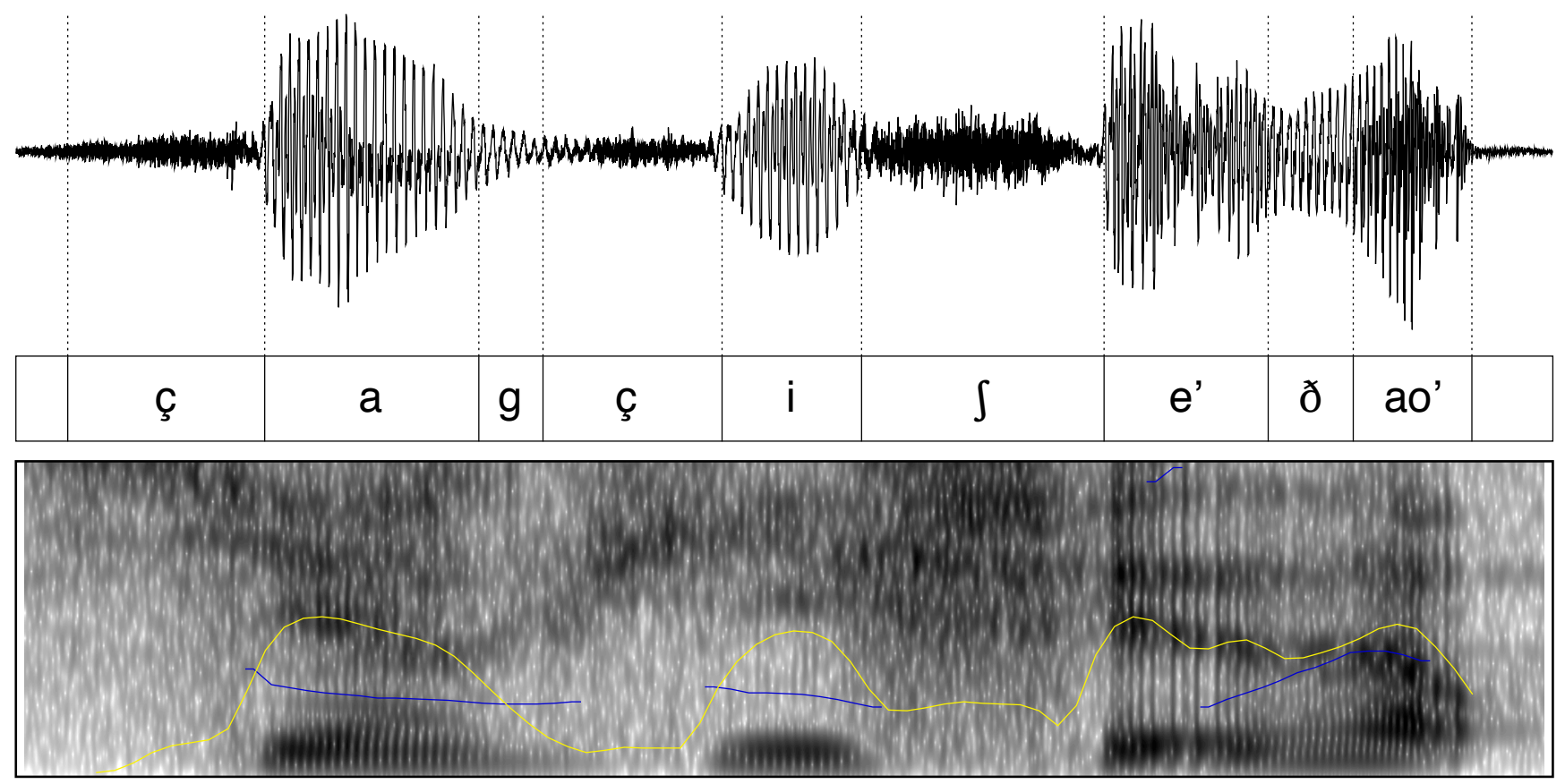

Fig. 6. Variably realised checked vowels 
(a) ja'da'o / ja'da'o / 'forest, jungle' (token 1)

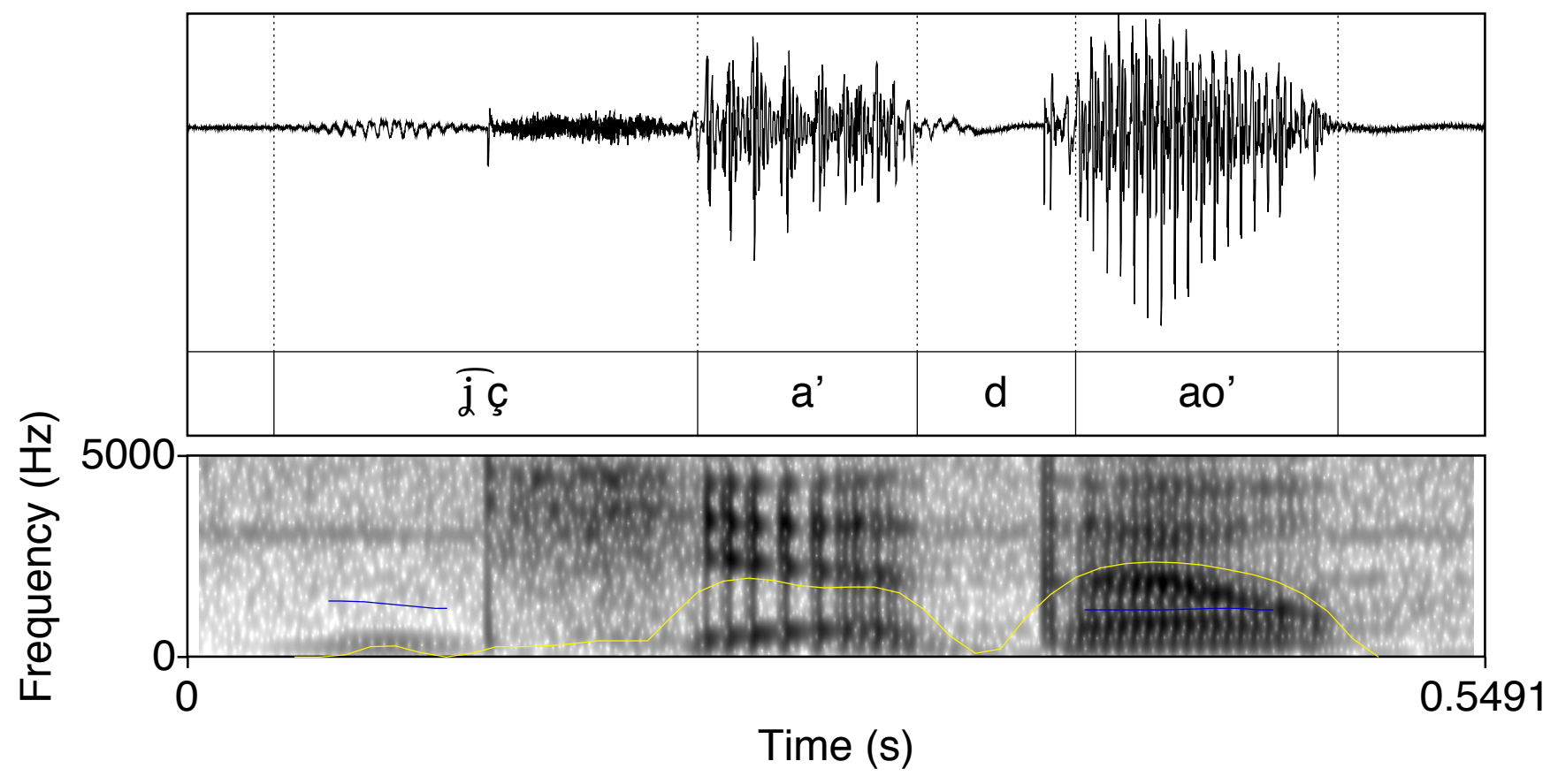

(b) ja'da'o / ja'da'o / 'forest, jungle' (token 2)

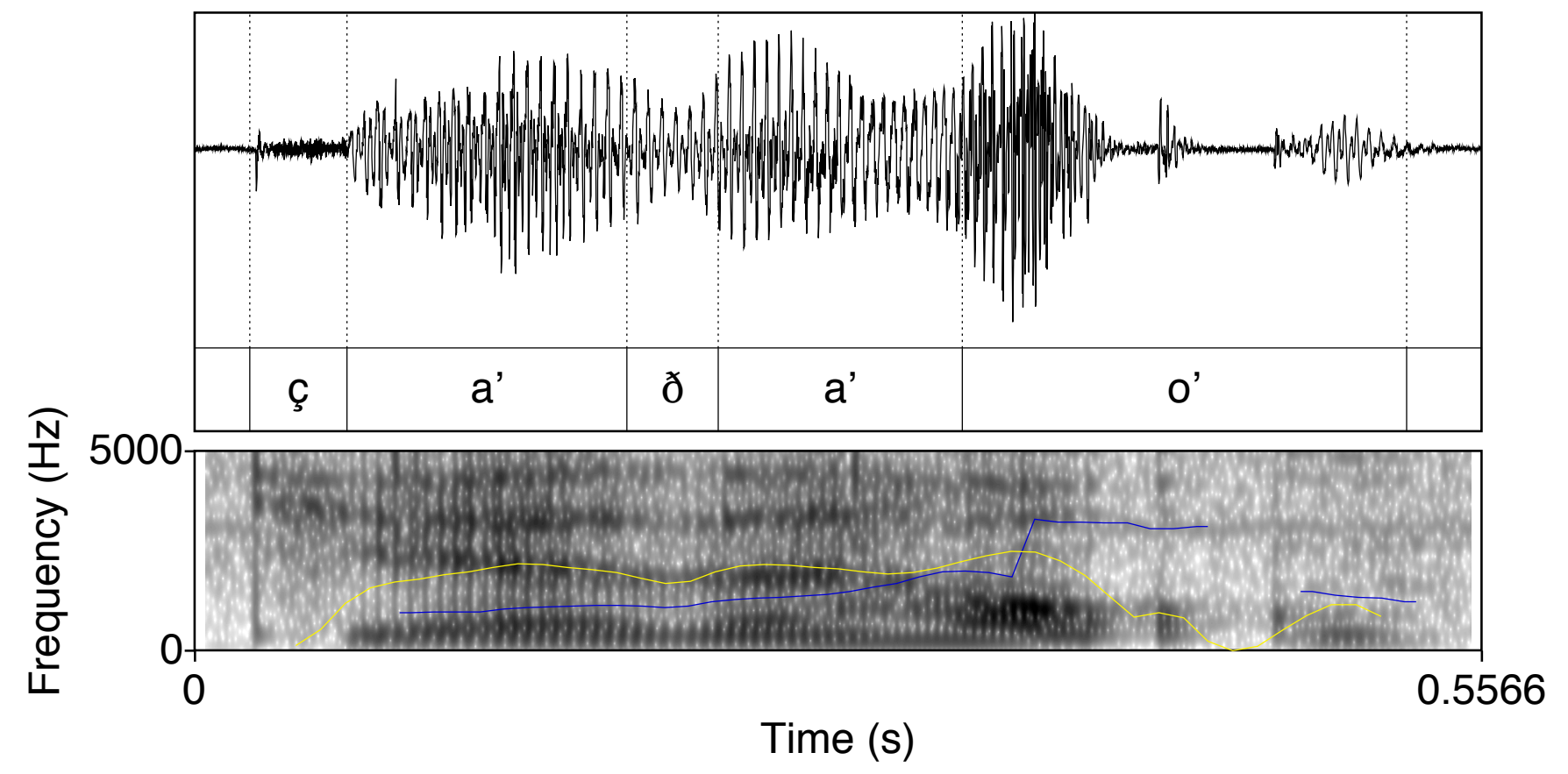

Fig. 7. Variation in nonfinal checked vowels. 
Figure 8. Short laryngealised syllables used in stimuli.

(a) $t e$

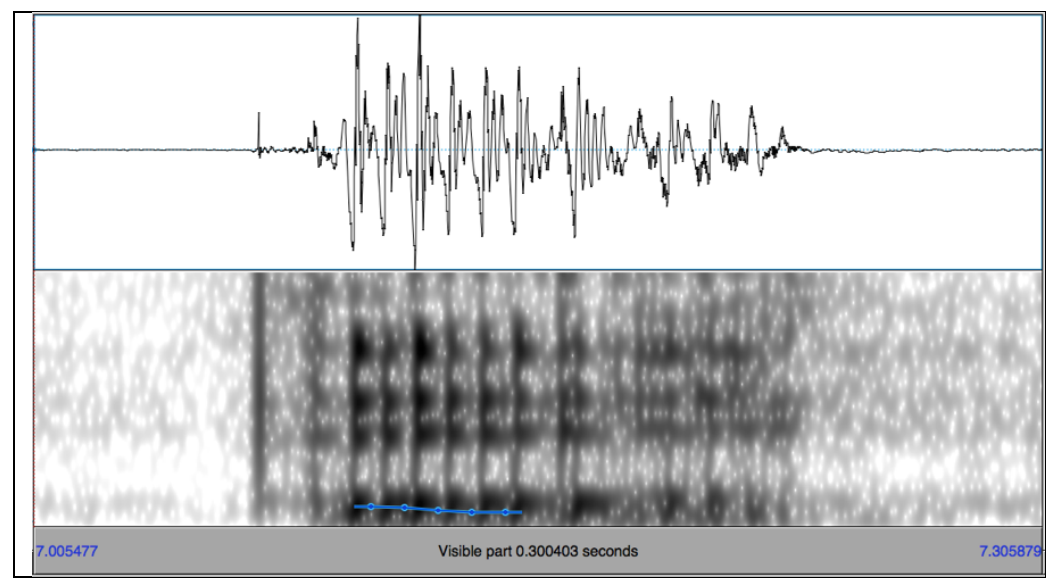

(b) $d e$

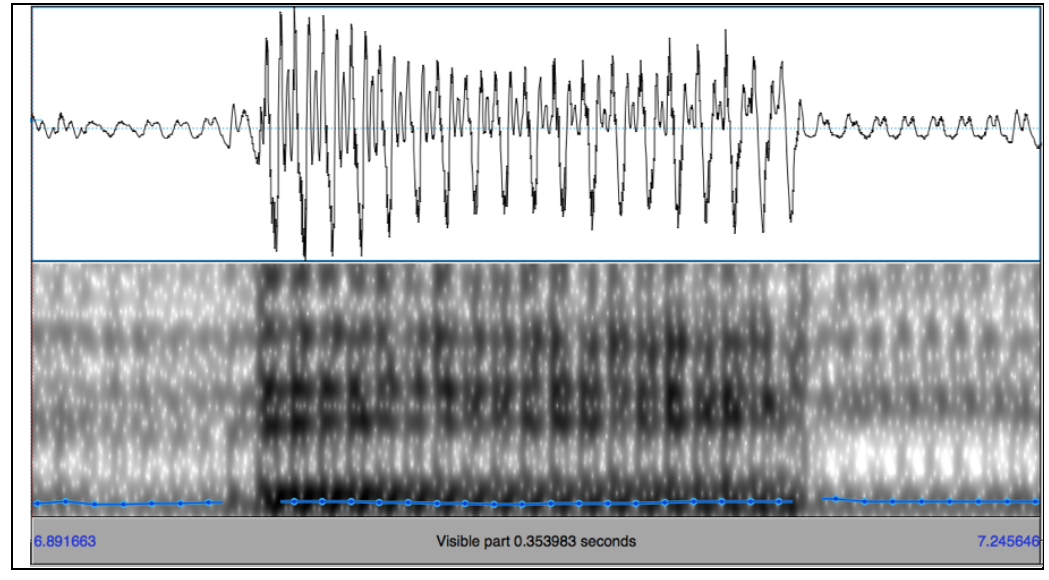

(c) $g e$

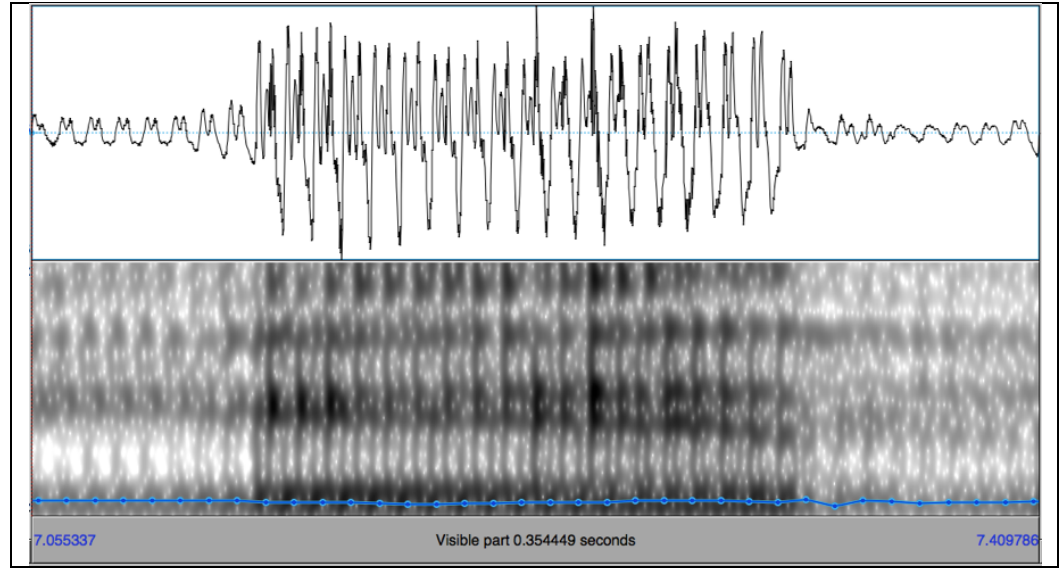


(d) $k e$

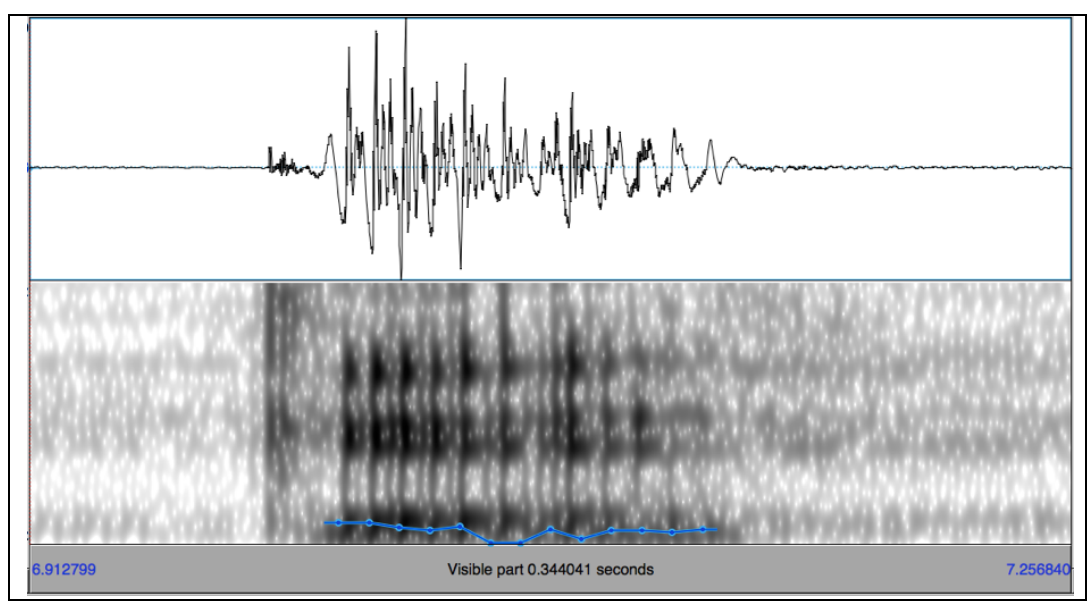


Figure 9. Velar laryngealised syllables used in stimuli.

(a) $d \underset{\sim}{e}$

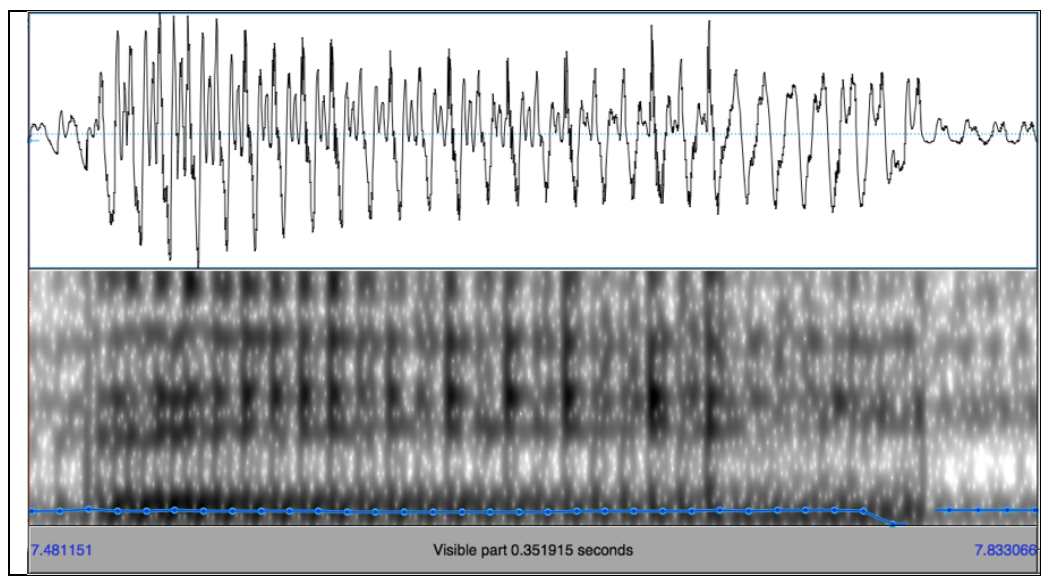

(b) $t e \underset{\sim}{e}$

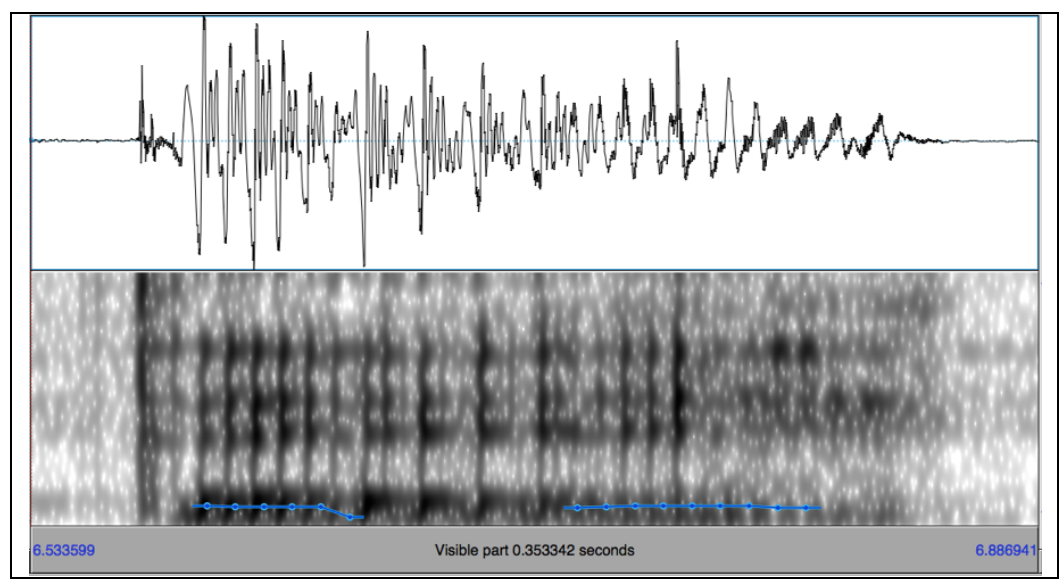

(c) gee

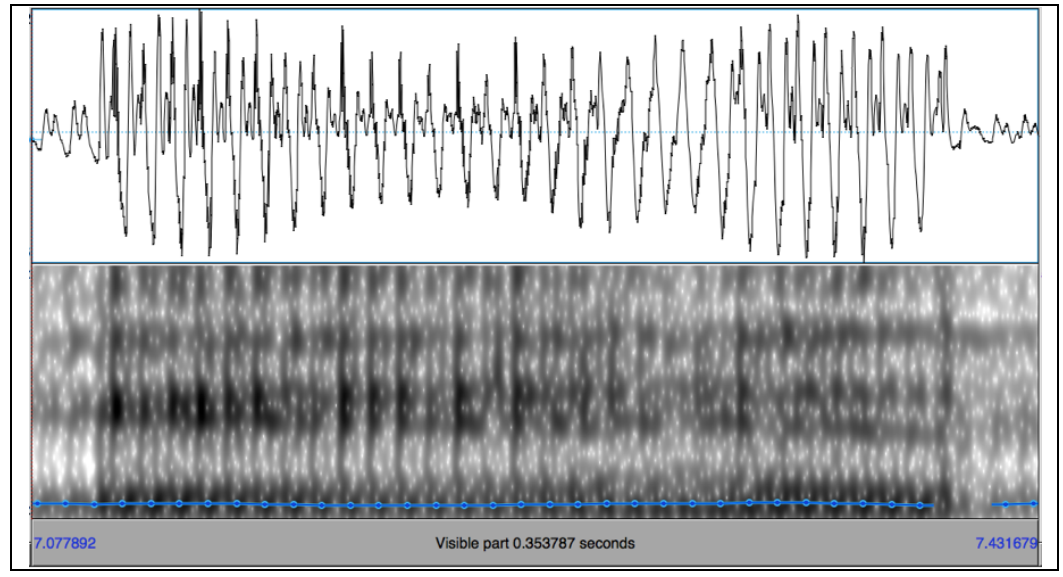


(d) ke $\underset{\sim}{e}$

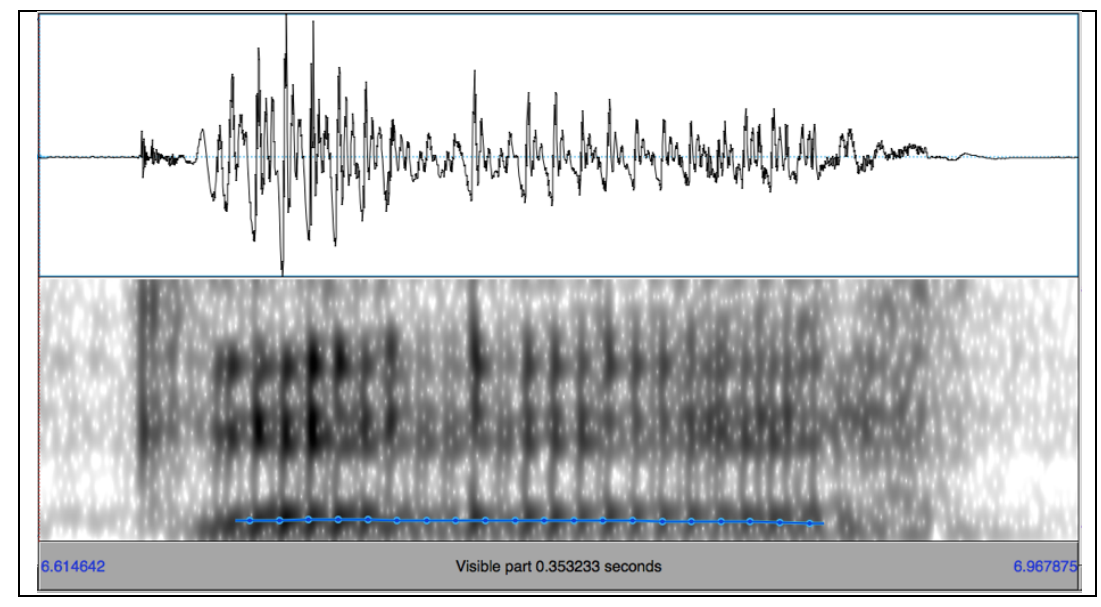


Fig. 10. Proportion of TeKe responses in the singly-varied Duration and Laryngeal conditions.

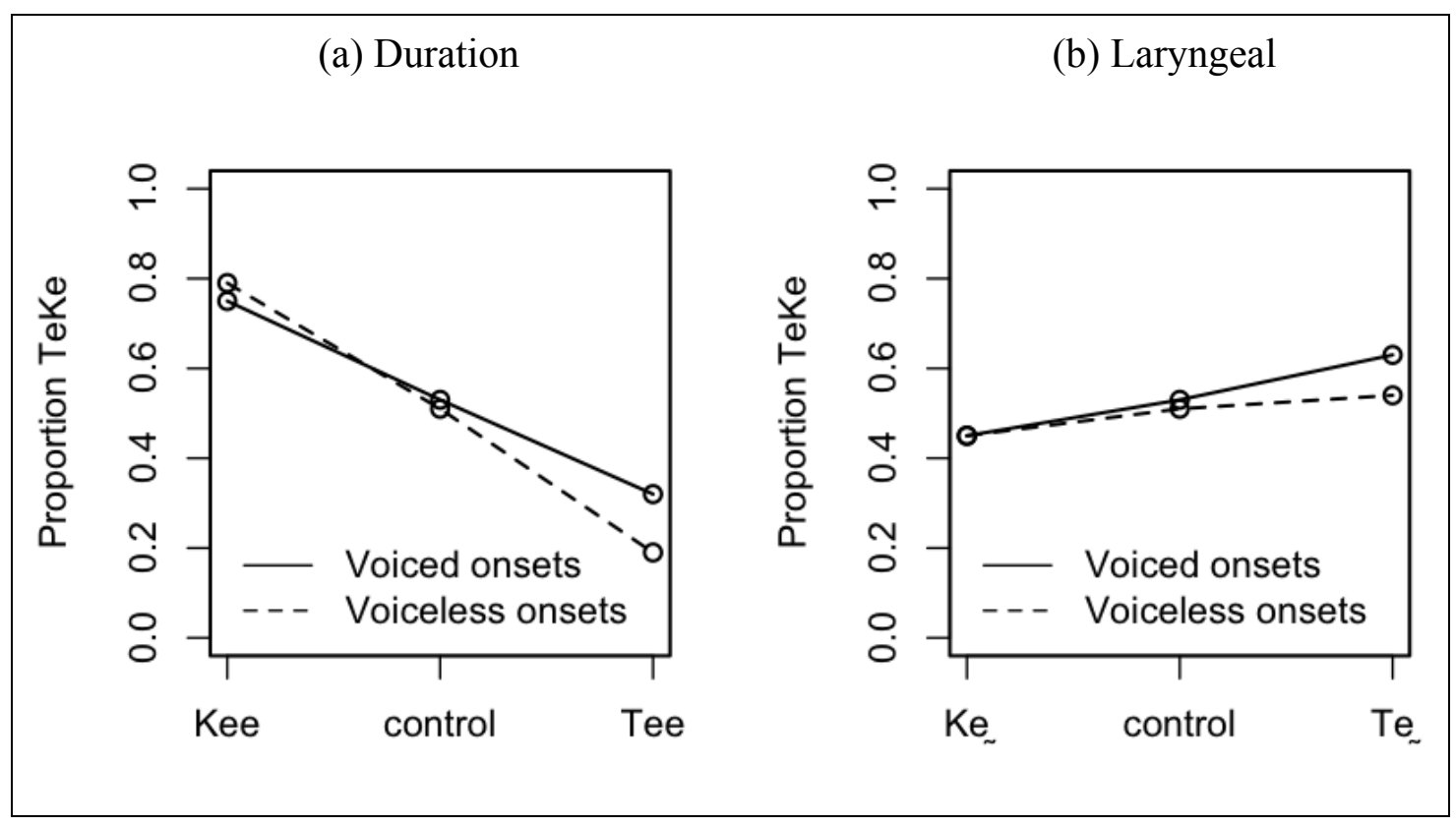


Figure 11. Proportion of TeKe responses in the control (white), Creak (mauve), Duration (salmon), Opposed (buff), and Overlapped (turquoise) conditions.

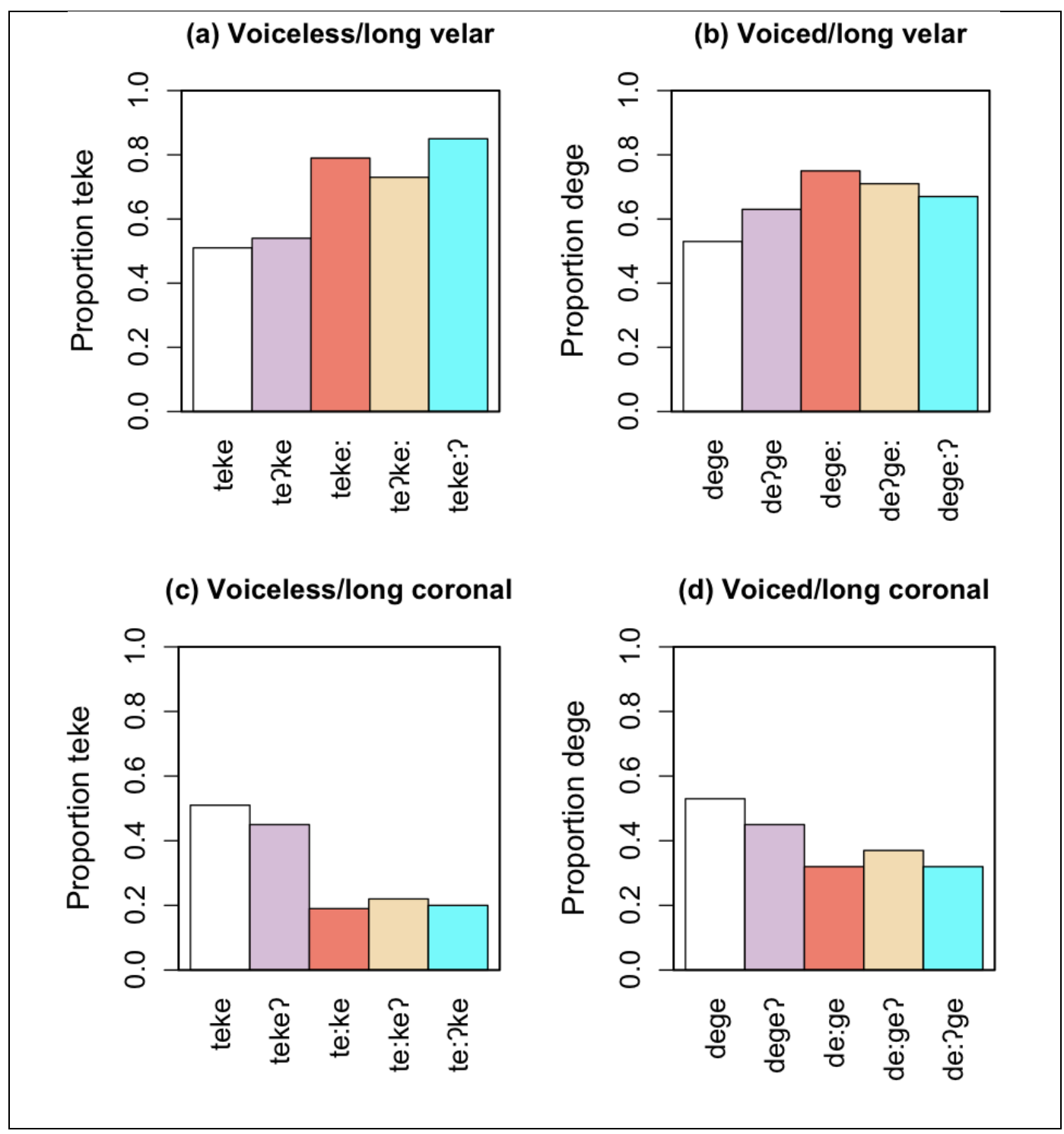


(a) labada' / labada' / 'gourd' (token 2)
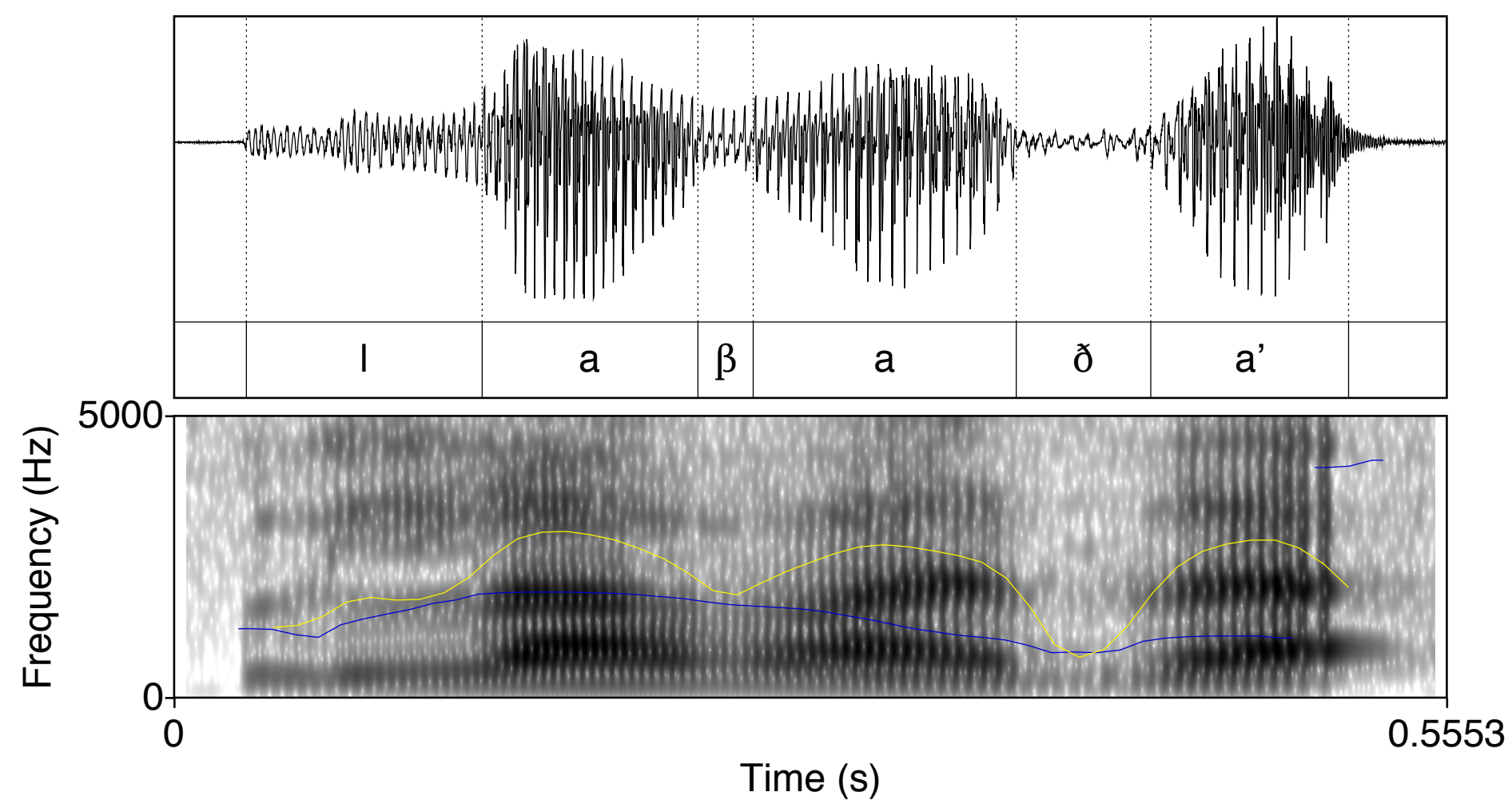

(b) labada' / labada' / 'gourd' (token 3)

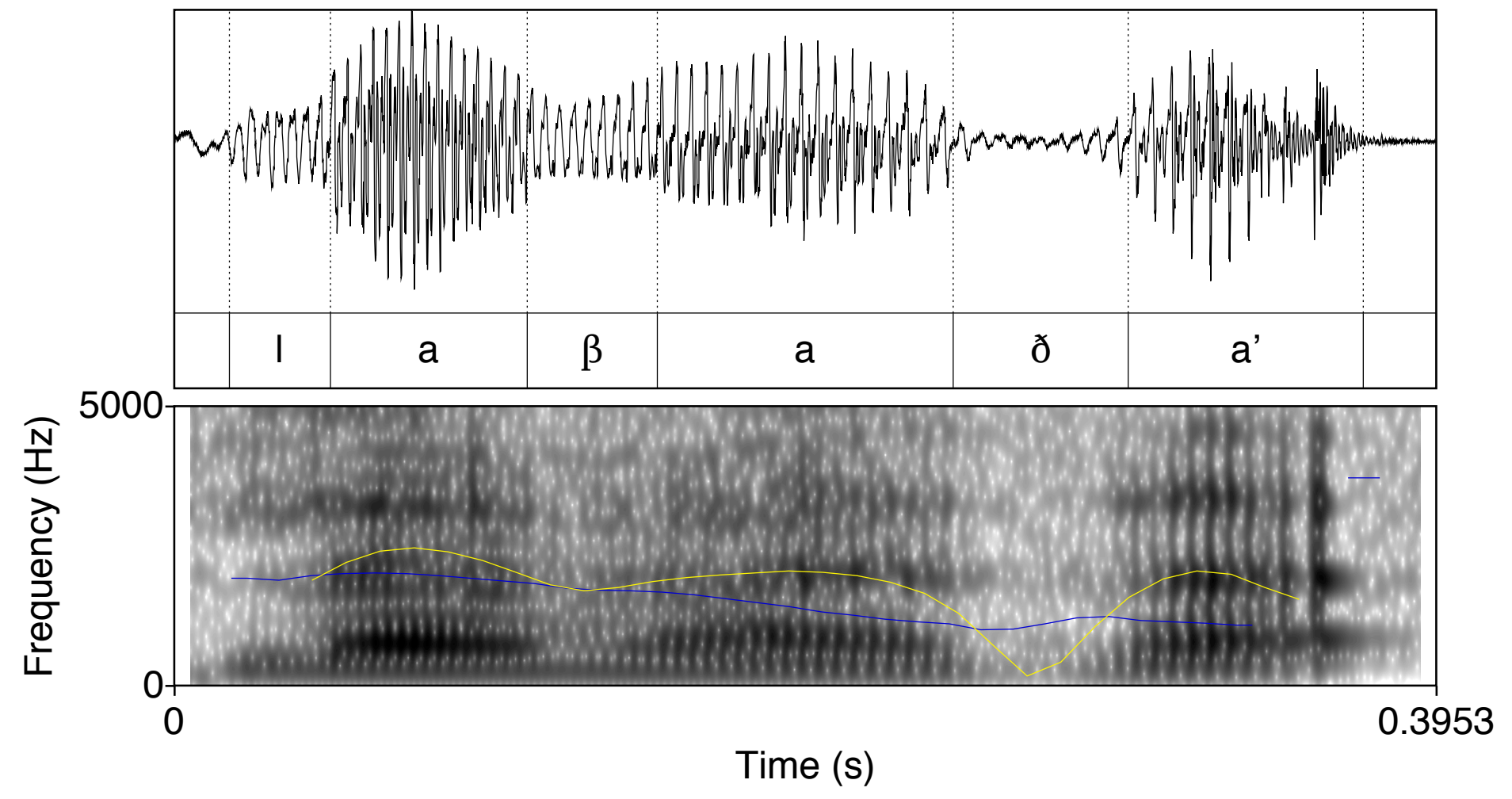

Fig. 12. Durational differences between penultimate stressed and final checked vowels. 